\title{
Sensitivity of aerosol and cloud effects on radiation to cloud types: comparison between deep convective clouds and warm stratiform clouds over one-day period
}

\author{
S. S. Lee ${ }^{1, *}$, L. J. Donner ${ }^{1}$, and V. T. J. Phillips ${ }^{1, * *}$ \\ ${ }^{1}$ Geophysical Fluid Dynamics Laboratory, Princeton University, Princeton, NJ, USA \\ *now at: Department of Atmospheric, Oceanic, and Space Science, University of Michigan, Ann Arbor, MI, USA \\ ** now at: Department of Meteorology, University of Hawaii, Manoa, HI, USA
}

Received: 27 May 2008 - Published in Atmos. Chem. Phys. Discuss.: 12 August 2008

Revised: 31 March 2009 - Accepted: 31 March 2009 - Published: 8 April 2009

\begin{abstract}
Cloud and aerosol effects on radiation in two contrasting cloud types, a deep mesoscale convective system (MCS) and warm stratocumulus clouds, are simulated and compared. At the top of the atmosphere, $45-81 \%$ of shortwave cloud forcing (SCF) is offset by longwave cloud forcing (LCF) in the MCS, whereas warm stratiform clouds show the offset of less than $\sim 20 \%$. 28\% of increased negative SCF is offset by increased LCF with increasing aerosols in the MCS at the top of the atmosphere. However, the stratiform clouds show the offset of just around $2-5 \%$. Ice clouds as well as liquid clouds play an important role in the larger offset in the MCS. Lower cloud-top height and cloud depth, characterizing cloud types, lead to the smaller offset of SCF by LCF and the offset of increased negative SCF by increased LCF at high aerosol in stratocumulus clouds than in the MCS. Supplementary simulations show that this dependence of modulation of LCF on cloud depth and cloud-top height is also simulated among different types of convective clouds.
\end{abstract}

\section{Introduction}

Among the many atmospheric processes that play a role in the Earth's radiation budget, clouds are among the most important and difficult to understand. Clouds affect the energy balance in the atmosphere by regulating the flow of radiation at the top of the atmosphere. This regulation process

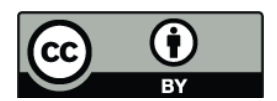

Correspondence to: S. S. Lee

(seoungl@umich.edu) is complicated by cloud microphysics involving numerous processes among different types of hydrometeors such as droplets, ice crystals, rain, snow, and hail. Also, increasing aerosols with industrialization are known to change cloud microphysics. Increasing aerosols decrease droplet size and increase cloud albedo (first aerosol indirect effect) and possibly suppress precipitation and alter cloud lifetime (second aerosol indirect effect). Uncertainties of radiative forcing associated with aerosol indirect effects are comparable to radiative forcing by an anthropogenic increase in green house gases (Ramaswamy et al., 2001).

Ramanathan et al. (1989) indicated that radiaitve properties of deep convective clouds were different from those of stratiform clouds, regarding the modulation of outgoing longwave radiation. Also, recent studies showed aerosols could change microphysical and dynamical properties of deep convective clouds (Khain et al., 2003, 2004, 2005, 2008; Lynn et al., 2005; Tao et al., 2007; Lee et al., 2008a). Lee et al. (2008b) found that aerosol effects on cloud mass and precipitation were different for deep convective and shallow stratiform clouds. Due to stronger interactions between microphysics and dynamics, increases in cloud mass were much larger in deep convective clouds than in shallow stratiform clouds for the same aerosol increases. This indicates that the response of radiation to aerosol increases can also be different for deep convective and stratiform clouds.

Systems like the Asian and Indian Monsoon, storm tracks, and ITCZ, playing important roles in global hydrologic and energy circulations, are driven by deep convective clouds, often organized into MCSs. Detrainment of ice crystals from deep convective clouds is the major source of ice anvils and cirrus in these systems. These cirrus clouds have significant

Published by Copernicus Publications on behalf of the European Geosciences Union. 
impacts on the global radiation budget (Ramanathan et al., 1989; Liou, 2005), and their radiative properties are mainly determined by ice-crystal formation and growth in deep convective clouds (Houze, 1993). Hence, aerosol effects on deep convective clouds can alter radiative properties of cirrus clouds and, thereby, global radiation budget. Especially those systems located over or near continents can be affected by aerosol changes significantly. Therefore, it is important to gain the understanding of how deep convective clouds (and their ice clouds) affect radiation and aerosols modify the effects of deep convective clouds on radiation.

This study aims to fulfill the following goals: 1) gain a preliminary understanding of how clouds and aerosols affect radiation in deep convection. 2) Examine how those cloud and aerosol effects in deep convection operate differently as compared to warm stratiform clouds, so as to find factors controlling the dependence of those effects on cloud types.

Integration design and aerosol descriptions are presented in Sect. 2. The results and summary and discussion are given in Sects. 3 and 4.

\section{Integration design and aerosol specification}

To fulfill goals of this study, cases of a stratocumulus cloud system and an observed deep MCS are simulated using a cloud-system-resolving model (CSRM) coupled with double-moment microphysics. The Weather Research and Forecasting (WRF) model is used as a CSRM. The CSRM used here is described in detail in Lee et al. (2008a). Impacts of the MCS on radiation and aerosol effects on radiation in the MCS are analyzed and compared to cloud and aerosol effects on radiation in warm marine stratiform clouds. This study also examines a role ice clouds play in radiation in the MCS.

The model domain has 2 dimensions. A mesoscale cloud system typically produces precipitation over areas $\sim 100 \mathrm{~km}$ or more in horizontal scale in at least one direction (Houze, 1993). Hence, for the simulation of the MCS, the model domain is set to $168 \mathrm{~km}$ in horizontal width. The model domain is $20 \mathrm{~km}$ deep. The horizontal grid length is $2 \mathrm{~km}$, and the vertical grid length is $500 \mathrm{~m}$. For shallower clouds, though, this resolution becomes problematic due to small-scale entrainment and detrainment processes at cloud top, which play important roles in the evolution of shallow stratiform clouds. Hence, finer resolution is used for the simulation of stratiform clouds but with smaller domain. The model domain is $26 \mathrm{~km}$ wide and $20 \mathrm{~km}$ deep. The horizontal grid length is set to $100 \mathrm{~m}$ and the vertical spacing is uniformly $40 \mathrm{~m}$ below $2.0 \mathrm{~km}$ and then stretched to $240 \mathrm{~m}$ near the model top.

Periodic boundary conditions are set on horizontal boundaries and a damping layer of $5 \mathrm{~km}$ depth is applied near the model top for simulations of both the MCS and stratiform clouds. Henceforth, the MCS and stratiform-cloud cases are referred to as "DEEP" and "SHALLOW", respectively.
Atmospheric Radiation Measurement (ARM) sub-case A (13:30 UTC 29 June-13:30 UTC 30 June 1997) observations provide large-scale forcings for DEEP. The sub-case A produced the largest precipitation rate among the 1997 IOP sub-cases through the development of a deep MCS. Sounding/profiler data were obtained every $3 \mathrm{~h}$ from the ARM SGP clouds and radiation testbed (CART) central facility located near Lamont, $\mathrm{OK}\left(36.61^{\circ} \mathrm{N}, 97.49^{\circ} \mathrm{W}\right)$ and from four boundary facilities. They were analyzed using a constrained variational objective analysis method by Zhang et al. (2001). The 3-hourly analyses were used to interpolate large-scale advection for potential temperature and specific humidity at every time step. Observed surface fluxes of heat and moisture were prescribed. To isolate better the different role of clouds and aerosols in radiation, differences in environmental conditions between DEEP and SHALLOW need to be minimized. For this, clouds in DEEP and SHALLOW are simulated for the same LST (local solar time) period at the same latitude on the same date. For SHALLOW, reanalysis data obtained every $6 \mathrm{~h}$ from the European Centre for Medium-Range Weather Forecasts (ECMWF) at $\left(36.61^{\circ} \mathrm{N}\right.$, $\left.74.99^{\circ} \mathrm{W}\right)(12: 00$ UTC 29 June-12:00 UTC 30 June 2002) were used to prescribe large-scale forcings and surface fluxes at every time step. Hence, nearly the same incident solar radiation is applied to those two types of clouds. Also, calculations described in the following Sect. 3.1 show the difference in surface longwave radiation flux between two types of clouds is within $\sim 5 \%$ relative to the flux in deep MCS. Therefore, both types of clouds are affected by similar radiation inputs from the top of the atmosphere (TOA) and the surface. The details of the procedure for applying large-scale forcings are described in Donner et al. (1999) and are similar to the method proposed by Grabowski et al. (1996). Horizontal momentum was damped to observed values, following Xu et al. (2002).

Two experiments are conducted for each of DEEP and SHALLOW. The first experiment uses predicted aerosol profiles from the Geophysical Fluid Dynamics Laboratory (GFDL) Global Atmosphere Model (AM2) with aerosol chemistry (nudged to analyzed fields) and is referred to as "high-aerosol run". The description of aerosol chemistry in the GFDL AM2 can be found in Lee et al. (2008a). The predicted mass profiles by the GFDL AM2, averaged over a one-day period, are obtained at $\left(36.61^{\circ} \mathrm{N}, 97.49^{\circ} \mathrm{W}\right)$ on 29 June 1997 and $\left(36.61^{\circ} \mathrm{N}, 74.99^{\circ} \mathrm{W}\right)$ on 29 June 2002 for DEEP and SHALLOW, respectively. Vertical profiles of the obtained aerosol, shown in Fig. 1a and c, are used for the high-aerosol run for DEEP and SHALLOW, respectively. The second experiment, referred to as "low-aerosol run", uses aerosol profiles where aerosol mass is reduced by a factor of 10 as compared to the high-aerosol run.

Sulfate, organic and salt aerosols are assumed to act only as cloud condensation nuclei $(\mathrm{CCN})$ and to have tri-modal lognormal size distributions. The mode diameter and standard deviation of the distributions, as well as the partitioning 

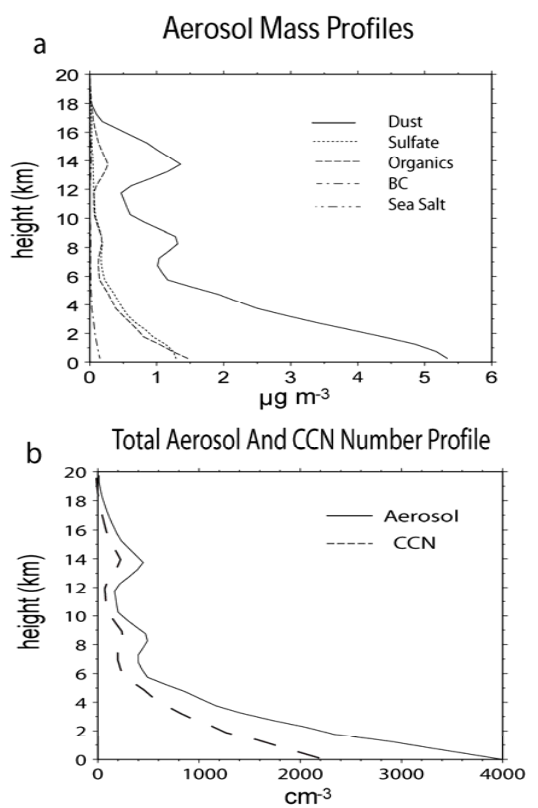
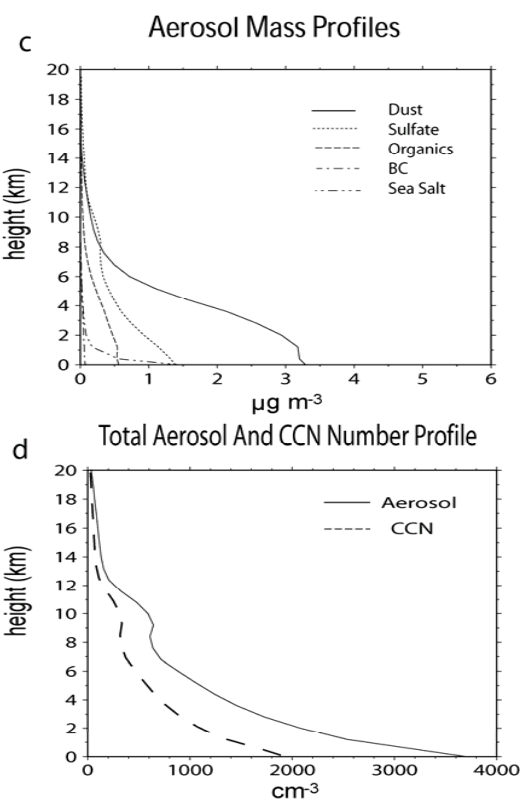

Fig. 1. Vertical profiles of (a) aerosol species and (b) total aerosol number and CCN number (at supersaturation of $1 \%$ ) for high aerosol runs in DEEP. Salt is present in (a), but its values are less than $0.01 \mu \mathrm{g} \mathrm{m}^{-3}$. (c and d) are the same as (a and b), respectively, but for SHALLOW.

among modes, are assumed to follow Whitby's (1978) values for clean continental air mass and not to vary spatiotemporally for both DEEP and SHALLOW. SHALLOW over the ocean adopts the same mode diameter, standard deviation and partitioning among modes of aerosol distributions as DEEP over the continent, since clouds in SHALLOW are just off the coast of Virginia where aerosols advected from the continent are likely to be dominant. Dust and black carbon (BC) aerosols are assumed to act only as ice nuclei (IN), since this study does not consider dust and BC aerosols coated by the sulfate which can act as CCN. Dust and BC aerosols obey uni-modal lognormal size distributions whose mode diameter and standard deviation are from Seinfeld and Pandis's (1998) values for remote continental areas. As assumed for aerosols acting as $\mathrm{CCN}$, mode diameter and standard deviation are assumed not to vary for those acting as IN.

Aerosol number concentration in each bin of the size spectrum is determined based on aerosol mass and aerosol particle density for each species using the assumed log-normal size distribution at each grid point. Figure $1 b$ and $d$ shows the vertical profile of the sum of aerosol number concentration over all aerosol species and the CCN number concentration at a supersaturation of $1 \%$ for DEEP and SHALLOW, respectively. Total aerosol number concentration at the surface is $\sim 4000 \mathrm{~cm}^{-3}$ for DEEP, a typical value in clean continental areas (Whitby, 1978), and $\sim 50 \%$ of aerosols are activated at a supersaturation of $1 \%$. For SHALLOW, total aerosol number concentration at the surface is $\sim 3600 \mathrm{~cm}^{-3}$ and $\sim 53 \%$ of aerosols are activated at a supersaturation of $1 \%$. Aerosols in the high-aerosol run in SHALLOW show a similar aerosol concentration at the surface to that in DEEP. This is because those stratiform clouds in SHALLOW are simulated just off the coast of Virginia where significant increases in aerosols advected from the continent were observed since industrialization. Hence, the comparison of the high- and low-aerosol runs for the case of stratiform clouds identifies aerosol effects for the similar transition of aerosol levels to that for the case of the MCS. This indicates that the MCS and stratiform clouds both are affected by a similar aerosol environment, minimizing differences in the aerosol level to contribute to the better isolation of the role of different effects on radiation from clouds and aerosols between the two types of clouds.

For the assumed log-normal size distribution with the constant standard deviation and mode radius here, the ratio of aerosol mass partitioned into each size bin of the distribution to total aerosol mass does not vary with total aerosol mass. Hence, a decrease in the total aerosol mass by a factor of 10 leads to 10-fold decreases in the partitioned aerosol mass in all size bins in the low-aerosol runs. This also leads to 10-fold decreases in aerosol number in each bin of the size distribution, since the identical particle density of each aerosol species is used for the high- and low-aerosol runs. Hence, the surface aerosol number concentration is $\sim 400 \mathrm{~cm}^{-3}$ in the low-aerosol runs, a typical value in maritime air (not affected by pollution) (Whitby, 1978). The comparison of the high- and low-aerosol runs identifies how a transition from maritime aerosols to rather polluted continental aerosols affects radiation. Depending on predicted aerosol mass within cloud, the total aerosol number for each aerosol species varies and is reset to the background value at all levels outside cloud. Within clouds, aerosols are advected, 
Table 1. Time- and area-averaged shortwave flux (SW) and longwave flux (LW) at the top (TOA) and base (SFC) of the atmosphere in DEEP. $\uparrow$ and $\downarrow$ denote upward and downward radiation, respectively.

\begin{tabular}{|c|c|c|c|c|c|c|c|c|c|c|c|c|c|c|}
\hline \multicolumn{15}{|c|}{$\begin{array}{l}\text { Time- and area-averaged radiation fluxes at the top and base of the model }\left(\mathrm{W} \mathrm{m}^{-2}\right) \\
\text { TOA }\end{array}$} \\
\hline & \multicolumn{2}{|c|}{$\mathrm{SW} \uparrow$} & \multicolumn{2}{|c|}{$\mathrm{SW} \downarrow$} & \multicolumn{2}{|c|}{$\begin{array}{c}\mathrm{SW} \\
(\mathrm{SW} \uparrow-\mathrm{SW} \downarrow)\end{array}$} & \multicolumn{2}{|c|}{$\mathrm{LW} \uparrow$} & \multicolumn{2}{|c|}{$\mathrm{LW} \downarrow$} & \multicolumn{2}{|c|}{$\begin{array}{c}\mathrm{LW} \\
(\mathrm{LW} \uparrow-\mathrm{LW} \downarrow)\end{array}$} & \multicolumn{2}{|c|}{$\mathrm{SW}+\mathrm{LW}$} \\
\hline & ALL & CLR & ALL & CLR & ALL & CLR & ALL & CLR & ALL & CLR & ALL & CLR & ALL & CLR \\
\hline Low aerosol & 97.20 & 85.15 & 478.53 & 478.53 & -381.33 & -393.38 & 266.86 & 276.63 & 0.00 & 0.00 & 266.86 & 276.63 & -114.47 & -116.75 \\
\hline High aerosol & 120.92 & 85.02 & 478.53 & 478.53 & -357.61 & -393.51 & 257.10 & 273.39 & 0.00 & 0.00 & 257.10 & 273.39 & -100.51 & -120.12 \\
\hline Observed & 111.65 & - & 477.15 & 477.15 & -365.50 & - & 260.23 & - & 0.00 & 0.00 & 260.23 & - & -105.27 & - \\
\hline $\begin{array}{l}\text { Difference } \\
\text { (high-low) }\end{array}$ & 23.72 & -0.13 & 0.00 & 0.00 & 23.72 & -0.13 & -9.76 & -3.24 & 0.00 & 0.00 & -9.76 & -3.24 & 13.96 & -3.37 \\
\hline \multicolumn{15}{|c|}{ SFC } \\
\hline & \multicolumn{2}{|c|}{$\mathrm{SW} \uparrow$} & \multicolumn{2}{|c|}{$\mathrm{SW} \downarrow$} & \multicolumn{2}{|c|}{$\begin{array}{c}\mathrm{SW} \\
(\mathrm{SW} \uparrow-\mathrm{SW} \downarrow)\end{array}$} & \multicolumn{2}{|c|}{$\mathrm{LW} \uparrow$} & \multicolumn{2}{|c|}{$\mathrm{LW} \downarrow$} & \multicolumn{2}{|c|}{$\begin{array}{c}\mathrm{LW} \\
(\mathrm{LW} \uparrow-\mathrm{LW} \downarrow)\end{array}$} & \multicolumn{2}{|c|}{$\mathrm{SW}+\mathrm{LW}$} \\
\hline & ALL & CLR & ALL & CLR & ALL & CLR & ALL & CLR & ALL & CLR & ALL & CLR & ALL & CLR \\
\hline Low aerosol & 60.43 & 70.63 & 316.53 & 371.57 & -256.10 & -300.94 & 442.10 & 442.10 & 365.61 & 361.85 & 76.49 & 80.25 & -179.61 & -220.69 \\
\hline High aerosol & 55.56 & 70.60 & 288.07 & 370.67 & -232.51 & -300.07 & 442.10 & 442.10 & 370.17 & 362.16 & 71.93 & 79.94 & -160.58 & -220.13 \\
\hline Observed & 54.64 & - & 279.44 & - & -224.80 & - & 453.99 & - & 397.12 & - & 56.87 & - & -167.93 & - \\
\hline $\begin{array}{l}\text { Difference } \\
\text { (high-low) }\end{array}$ & -4.87 & -0.03 & -28.46 & -0.90 & 23.59 & 0.87 & 0.00 & 0.00 & 4.56 & 0.31 & -4.56 & -0.31 & 19.03 & 0.56 \\
\hline
\end{tabular}

diffused and depleted by nucleation (nucleation scavenging). Initially aerosol mass mixing ratio is everywhere set equal to its background value. Background aerosol number concentrations for all aerosol species in each aerosol size mode are assumed not to vary with time, since the variation of the extracted aerosols from GFDL AM2 is not significant on the date of simulations.

This study focuses on aerosol effects on the nucleation of cloud particles and thereby cloud microphysical and radiative properties and, thus, does not take into account aerosol direct effects on radiation. In other words, aerosol impacts on cloud-particle properties after its activation are only taken into account.

\section{Results}

\subsection{Radiation fluxes}

The all- and clear-sky radiative fluxes for shortwave and longwave radiation are obtained. The clear-sky fluxes are diagnosed by setting the mixing ratios of all the hydrometeors to zero with all the other variables unchanged at every time step for the high- and low-aerosol runs, respectively. Henceforth, the clear-sky condition is referred to as "CLR" and the all-sky as "ALL." Radiation fluxes are shown in Tables 1 and 2 for DEEP and SHALLOW, respectively ( $\uparrow$ and $\downarrow$ denote upward and downward fluxes, respectively, and minus signs indicate downward net flux). In Tables, SW and $\mathrm{LW}$ represent shortwave flux and longwave flux, respectively. Table 3 shows SCF, LCF, and cloud radiative forcing (CRF), which is SCF+LCF, in DEEP and SHALLOW. Cloud forcing here is defined as CLR - ALL. The role of ice clouds in DEEP is diagnosed by setting the mixing ratio of all icephase hydrometeors to zero with all the other variables unchanged at every time step for the high- and low-aerosol runs. Henceforth, this ice-free condition is referred to as "DEEP (LIQ)" and cloud forcing in DEEP (LIQ) is presented in Table 3. The comparison of DEEP (LIQ) to DEEP identifies the role of ice clouds in radiation.

Differences in individual upward and downward fluxes between the high-aerosol run and observation in DEEP are within $\sim 10 \%$ of observed fluxes. The size and path of cloud particles (i.e., cloud liquid and cloud ice) play important roles in determining the impacts of clouds on radiative fluxes. Hence, one or both of simulated size and path of cloud particles are compared to the observation, depending on the availability of observed data. The domain-averaged liquid-water path (LWP) is $51 \mathrm{~g} \mathrm{~m}^{-2}$. This LWP is within $\sim 10 \%$ of the observed LWP $\left(55 \mathrm{~g} \mathrm{~m}^{-2}\right)$. Thus, clouds in DEEP can be considered to be simulated reasonably well for the calculation of radiation. The LWP is observed by the microwave radiometer and corrections are made to eliminate the contamination by raindrops on the instrument as described in Liljegren (1994). The comparisons for the size of cloud liquid and the size and path of cloud ice are not viable here, since the 1997 ARM observation does not provide those data, though more recent ARM observations after the year 2000 started to provide those data. Simulated LWP and effective size in SHALLOW are compared to observation by the Moderate Resolution Imaging Spectroradiometer (MODIS) to assess the ability of the model to simulate stratiform clouds; comparisons for radiative fluxes are not viable here, since the MODIS data do not provide observed fluxes. The effective size in this study is in diameter. The domain-averaged simulated LWP is $56.20 \mathrm{~g} \mathrm{~m}^{-2}$ and MODIS-observed LWP 
Table 2. Time- and area-averaged SW and LW at the top (TOA) and base (SFC) of the atmosphere in SHALLOW.

\begin{tabular}{|c|c|c|c|c|c|c|c|c|c|c|c|c|c|c|}
\hline \multicolumn{15}{|c|}{$\begin{array}{c}\text { Time- and area-averaged radiation fluxes at the top and base of the model }\left(\mathrm{W} \mathrm{m}^{-2}\right) \\
\text { TOA }\end{array}$} \\
\hline & \multicolumn{2}{|c|}{$\mathrm{SW} \uparrow$} & \multicolumn{2}{|c|}{$\mathrm{SW} \downarrow$} & \multicolumn{2}{|c|}{$\begin{array}{c}\mathrm{SW} \\
(\mathrm{SW} \uparrow-\mathrm{SW} \downarrow)\end{array}$} & \multicolumn{2}{|c|}{$\mathrm{LW} \uparrow$} & \multicolumn{2}{|c|}{$\mathrm{LW} \downarrow$} & \multicolumn{2}{|c|}{$\begin{array}{c}\mathrm{LW} \\
(\mathrm{LW} \uparrow-\mathrm{LW} \downarrow)\end{array}$} & \multicolumn{2}{|c|}{ SW+LW } \\
\hline & ALL & CLR & ALL & CLR & ALL & CLR & ALL & CLR & ALL & CLR & ALL & CLR & ALL & CLR \\
\hline Low aerosol & 93.11 & 38.24 & 478.53 & 478.53 & -385.42 & -440.29 & 274.26 & 283.25 & 0.00 & 0.00 & 274.26 & 283.25 & -111.16 & -157.04 \\
\hline High aerosol & 111.21 & 38.12 & 478.53 & 478.53 & -367.32 & -440.41 & 273.46 & 282.90 & 0.00 & 0.00 & 273.46 & 282.90 & -93.86 & -157.51 \\
\hline Observed & - & - & - & - & - & - & - & - & - & - & - & - & - & - \\
\hline $\begin{array}{l}\text { Difference } \\
\text { (high-low) }\end{array}$ & 18.10 & -0.12 & 0.00 & 0.00 & 18.10 & -0.12 & -0.80 & -0.35 & 0.00 & 0.00 & -0.80 & -0.35 & 17.30 & -0.47 \\
\hline \multicolumn{15}{|c|}{ SFC } \\
\hline & \multicolumn{2}{|c|}{$\mathrm{SW} \uparrow$} & \multicolumn{2}{|c|}{$\mathrm{SW} \downarrow$} & \multicolumn{2}{|c|}{$\begin{array}{c}\mathrm{SW} \\
(\mathrm{SW} \uparrow-\mathrm{SW} \downarrow)\end{array}$} & \multicolumn{2}{|c|}{$\mathrm{LW} \uparrow$} & \multicolumn{2}{|c|}{$\mathrm{LW} \downarrow$} & \multicolumn{2}{|c|}{$\begin{array}{c}\mathrm{LW} \\
(\mathrm{LW} \uparrow-\mathrm{LW} \downarrow)\end{array}$} & \multicolumn{2}{|c|}{ SW+LW } \\
\hline & ALL & CLR & ALL & CLR & ALL & CLR & ALL & CLR & ALL & CLR & ALL & CLR & ALL & CLR \\
\hline Low aerosol & 23.92 & 27.02 & 319.62 & 374.75 & -295.70 & -347.73 & 424.60 & 424.60 & 356.69 & 350.35 & 67.91 & 74.25 & -227.79 & -273.48 \\
\hline High aerosol & 21.32 & 26.73 & 298.19 & 373.89 & -276.87 & -347.16 & 425.14 & 425.14 & 357.76 & 350.02 & 67.38 & 75.12 & -209.49 & -272.04 \\
\hline Observed & - & - & - & - & - & - & - & - & - & - & - & - & - & - \\
\hline $\begin{array}{l}\text { Difference } \\
\text { (high-low) }\end{array}$ & -2.60 & -0.29 & -21.43 & -0.86 & 18.83 & 0.57 & 0.54 & 0.54 & 1.07 & -0.33 & -0.53 & 0.87 & 18.30 & 1.44 \\
\hline
\end{tabular}

Table 3. Time- and area-averaged TOA and SFC shortwave cloud forcing (SCF), longwave cloud forcing (LCF), and cloud radiative forcing (CRF) $\left(\mathrm{W} \mathrm{m}^{-2}\right)$, i.e. SCF+LCF, for DEEP, SHALLOW and DEEP (LIQ).

\begin{tabular}{|c|c|c|c|c|c|c|c|c|c|}
\hline \multicolumn{10}{|c|}{ TOA $\left(\mathrm{W} \mathrm{m}^{-2}\right)$} \\
\hline & \multicolumn{3}{|c|}{$\mathrm{SCF}$} & \multicolumn{3}{|c|}{ LCF } & \multicolumn{3}{|c|}{$\mathrm{CRF}$} \\
\hline & DEEP & SHALLOW & DEEP (LIQ) & DEEP & SHALLOW & DEEP (LIQ) & DEEP & SHALLOW & DEEP (LIQ) \\
\hline Low aerosol & -12.05 & -54.87 & -4.97 & 9.77 & 8.99 & 2.11 & -2.28 & -45.88 & -2.86 \\
\hline High aerosol & -35.90 & -73.09 & -18.08 & 16.29 & 9.44 & 4.52 & -19.61 & -63.65 & -13.56 \\
\hline $\begin{array}{l}\text { Difference } \\
\text { (high-low) }\end{array}$ & -23.85 & -18.22 & -13.11 & 6.52 & 0.45 & 2.41 & -17.33 & -17.77 & -10.70 \\
\hline \multicolumn{10}{|c|}{$\operatorname{SFC}\left(\mathrm{W} \mathrm{m}^{-2}\right)$} \\
\hline & \multicolumn{3}{|c|}{ SCF } & \multicolumn{3}{|c|}{ LCF } & \multicolumn{3}{|c|}{$\mathrm{CRF}$} \\
\hline & DEEP & SHALLOW & DEEP (LIQ) & DEEP & SHALLOW & DEEP (LIQ) & DEEP & SHALLOW & DEEP (LIQ) \\
\hline Low aerosol & -44.84 & -52.03 & -10.24 & 3.76 & 6.34 & 0.88 & -41.08 & -45.69 & -9.36 \\
\hline High aerosol & -67.56 & -70.29 & -21.38 & 8.01 & 7.74 & 2.64 & -59.55 & -62.55 & -18.74 \\
\hline $\begin{array}{l}\text { Difference } \\
\text { (high-low) }\end{array}$ & -22.72 & -18.26 & -11.14 & 4.25 & 1.40 & 1.76 & -18.47 & -16.86 & -9.38 \\
\hline
\end{tabular}

at the location of simulation is $59.35 \mathrm{~g} \mathrm{~m}^{-2}$. In-cloud average effective size of simulated cloud liquid is $18.56 \mu \mathrm{m}$ and MODIS-observed size is $17.10 \mu \mathrm{m}$. Hence, differences are within $\sim 10 \%$, demonstrating that clouds in SHALLOW are reasonably well simulated.

SCF is counterbalanced substantially more by LCF at the top of the atmosphere in each high- and low-aerosol runs in DEEP than in SHALLOW (Table 3). At the top of the atmosphere, $45 \%(81 \%)$ of SCF is counterbalanced by LCF in the high-aerosol run (low-aerosol run) in DEEP. However, in SHALLOW, just $13 \%(16 \%)$ of SCF is counterbalanced in the high-aerosol run (low-aerosol run). At the bottom of the atmosphere, differences in the counterbalance between DEEP and SHALLOW are negligible as compared to those at the top. Larger counterbalance in deep convective clouds than in shallow stratiform clouds at the top of the atmosphere is also observed by Ramanathan et al. (1989). They found that SCF was substantially counterbalanced by the reduction of outgoing LW in deep convective regions mainly associated with Asian and Indian Monsoon, storm tracks, and ITCZ. However, their data indicated that the counterbalance in the regions of stratiform clouds was not as strong as in deep convective regions.

The high-aerosol run shows larger negative SCF by 23.85 and $18.22 \mathrm{~W} \mathrm{~m}^{-2}$ than the low-aerosol run at the top in DEEP and SHALLOW, respectively (Table 3 ). This is mainly because more SW is reflected in the high-aerosol run than in the low-aerosol run by $23.72 \mathrm{~W} \mathrm{~m}^{-2}$ and $18.10 \mathrm{~W} \mathrm{~m}^{-2}$ in 

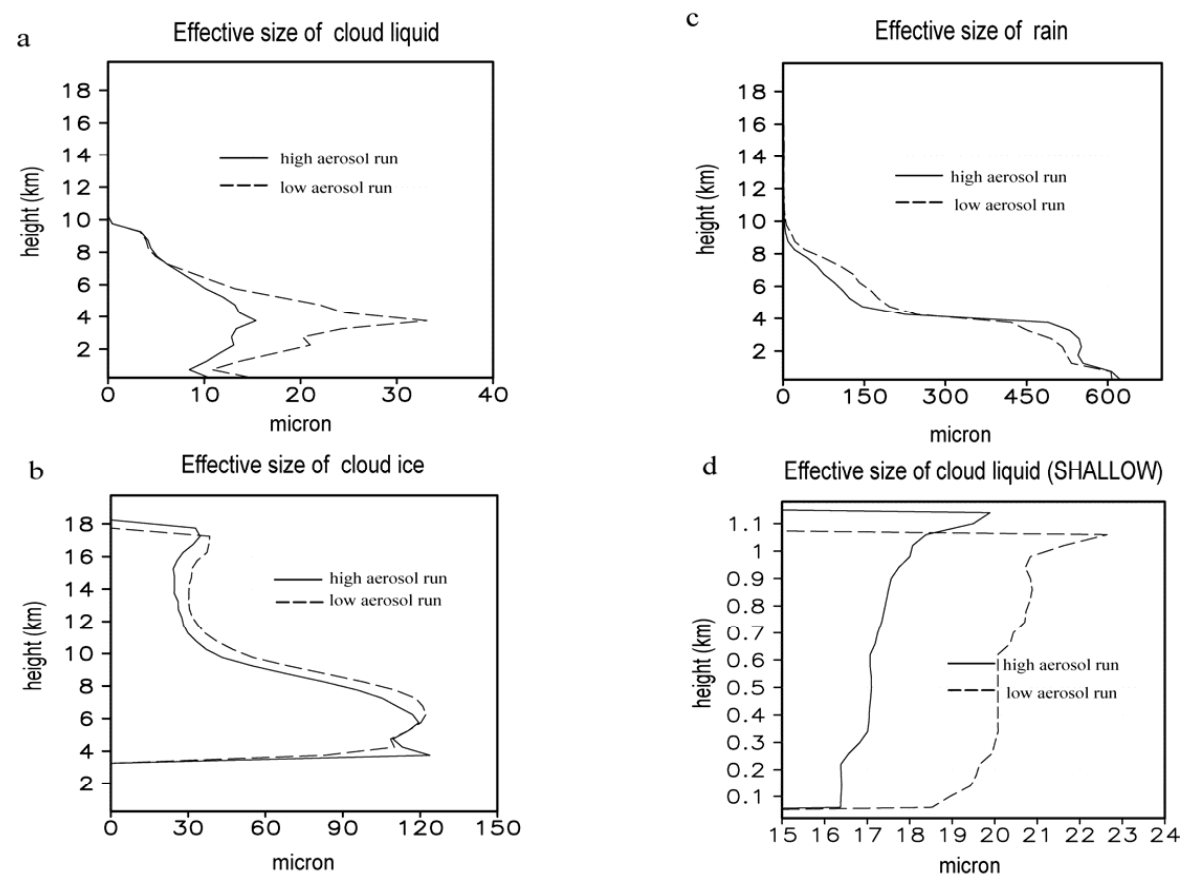

Fig. 2. Vertical distribution of in-cloud average effective size (in diameter) of (a) cloud liquid, (b) cloud ice and (c) rain in DEEP. (d) is the same as (a) but for SHALLOW. The bottom of each figure corresponds to the lowest grid point of the atmosphere which is 250 (20) $\mathrm{m}$ for DEEP (SHALLOW).

DEEP and SHALLOW, respectively, as shown in Tables 1 and 2. Since clouds in the high-aerosol run decrease the outgoing LW more than in the low-aerosol run in both DEEP and SHALLOW (Tables 1 and 2), LCF is larger in the highaerosol run than in the low-aerosol run by $6.52 \mathrm{~W} \mathrm{~m}^{-2}$ and $0.45 \mathrm{~W} \mathrm{~m}^{-2}$ in DEEP and SHALLOW, respectively, at the top (Table 3). Thus, similar to the larger compensation of SCF by LCF in each of the high- and low-aerosol runs in DEEP than in SHALLOW at the top, the variation of SCF due to aerosol changes is offset by that of LCF much more in DEEP than in SHALLOW. 28\% of an increase of negative SCF due to aerosol increases is offset by that of LCF in DEEP, whereas SHALLOW shows the offset of just $2 \%$ at the top. DEEP also shows significantly larger offset (19\%) of the aerosol-induced changes in SCF by those in LCF than that $(2 \%)$ in SHALLOW at the bottom.

In the absence of ice clouds in DEEP (LIQ), the offset of SCF by LCF is reduced to $42 \%$ (25\%) in the high-aerosol run (low-aerosol run) as compared to those in the presence of ice clouds (DEEP) at the top (Table 3). However, still, the offset in each high-aerosol run and low-aerosol run in DEEP (LIQ) is larger than in SHALLOW. The offset of increased negative SCF by increased LCF with increasing aerosols is also reduced to $18 \%$ in the absence of ice clouds at the top in DEEP (LIQ). However, the offset in DEEP (LIQ) is also still larger than that in SHALLOW.
Results here indicate that deep convective clouds affect the radiation budget quite differently as compared to stratiform clouds in terms of the modulation of LW. They also indicate that the aerosol-induced modulation of LW can substantially offset that of SW in deep convective clouds, which has not been considered in most GCM studies. To gain understanding of these different responses of radiation between deep convective and shallow clouds, the effective size and mass of hydrometeors, which determine the radiative properties of clouds, are examined.

\subsection{Microphysical properties of clouds}

Figure 2a-c shows the profiles of effective size, and Fig. 3a$\mathrm{c}$, the profiles of the contents of cloud liquid, cloud ice, and rain in DEEP. Since hail is treated radiatively in the same manner as for snow in DEEP, they are treated as one hydrometeor entity, referred to as "snow+hail", and the vertical profile of the sum is depicted in Fig. 3d. During time integration, heights of cloud bases vary mostly from $\sim 0.25 \mathrm{~km}$ (corresponding to the bottom of Figs. $2 \mathrm{a}-\mathrm{c}$ and $3 \mathrm{a}-\mathrm{d}$ ) to $\sim 2 \mathrm{~km}$ due to spatiotemporally varying large-scale forcing and perturbed humidity and temperature fields by preexisting clouds. The freezing level is $\sim 4 \mathrm{~km}$. The effective size of snow+hail is prescribed as $150 \mu \mathrm{m}$ for both runs in DEEP. Only the vertical profiles of effective size and contents of cloud liquid are presented for SHALLOW in Figs. $2 d$ and 3e, since stratiform clouds in SHALLOW are warm clouds where ice processes 


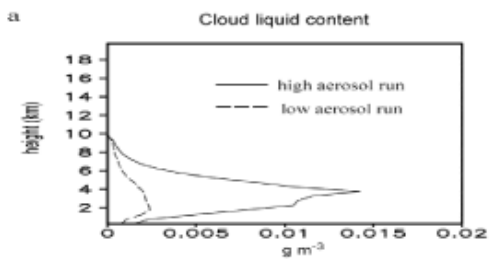

b
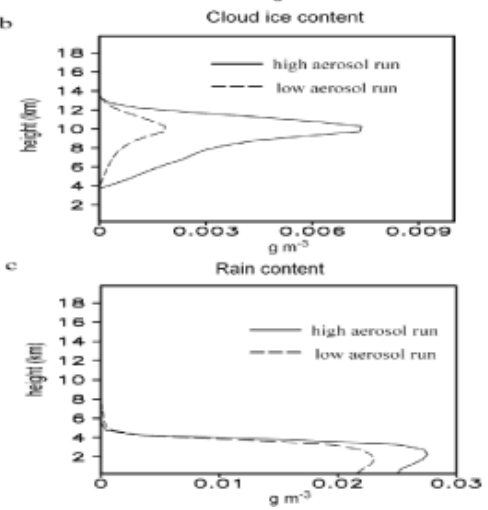
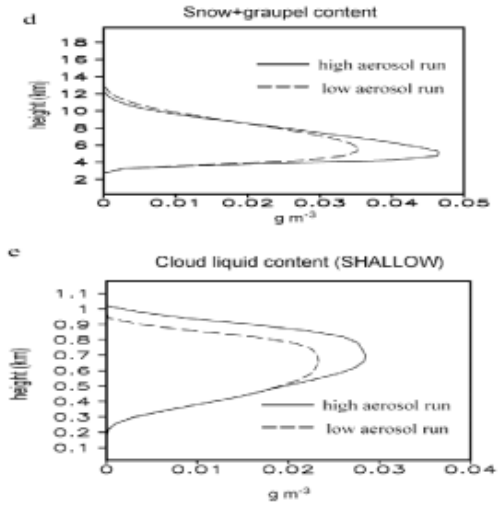

Fig. 3. Time- and domain-averaged vertical distribution of contents of (a) cloud liquid, (b) cloud ice, (c) rain and (d) snow+hail. (e) is the same as (a) but for SHALLOW. The bottom of each figure corresponds to the lowest grid point of the atmosphere which is 250 (20) $\mathrm{m}$ for DEEP (SHALLOW).

are not present with negligible precipitation. Average precipitation rate is smaller than $0.01 \mathrm{~mm} \mathrm{day}^{-1}$ in both the highand low-aerosol runs in SHALLOW. The contribution of rain and snow thail to radiation budgets is negligible as compared to that of cloud liquid and cloud ice in DEEP, because their particle sizes are generally larger than the radiation wavelengths. Hence, this study focuses on the role of cloud liquid and cloud ice in radiation among hydrometeors.

The role of cloud liquid, accounting for larger fraction of total cloud-particle (cloud liquid and cloud ice) mass than cloud ice in DEEP and all cloud mass in SHALLOW (see Fig. 3a, b and e), in radiation are first examined. Timeand domain-average liquid-water content (LWC) is 0.0025 (0.0020) and $0.0006(0.0013) \mathrm{g} \mathrm{m}^{-3}$ in the high- and lowaerosol runs, respectively, in DEEP (SHALLOW). Although in-cloud average LWC is larger in DEEP than in SHALLOW, domain-average LWC is lower at low aerosol due to lower cloud fraction in DEEP than in SHALLOW. Cloud fractions averaged over all the time steps and a layer between minimum cloud-base height and maximum cloud-top height at low aerosol in DEEP and SHALLOW are 0.27 and 0.90 , respectively. For the calculation of in-cloud averaged values and cloud fraction, it is needed to determine the grid points in cloud. Grid points are assumed to be in cloud if the number concentration and volume-mean size of droplets is typical for clouds and fogs $\left(1 \mathrm{~cm}^{-3}\right.$ or more, $1 \mu \mathrm{m}$ or more; Pruppacher and Klett, 1997). To calculate the in-cloud average of a variable of interest, first, the conditional average over the grid points in cloud is obtained at each time step; the conditional average is the arithmetic mean of the vari- able over collected grid points in cloud (grid point in clear air is excluded from the collection). Then, those conditional averages are collected and averaged over time to obtain the in-cloud average in this study; only time steps with non-zero conditional averages are included in the collection over time. The domain-average difference in LWC at high aerosol between DEEP and SHALLOW is smaller than the in-cloud average difference due to lower averaged cloud fraction $(0.32)$ in DEEP than that (0.95) in SHALLOW.

Larger LWC in DEEP than in SHALLOW in the highaerosol run favors more absorption of LW emitted from the surface, contributing to the larger offset of SCF by LCF in DEEP than in SHALLOW (Table 3). The comparison of DEEP (LIQ) to SHALLOW indicates liquid clouds alone can lead to larger offset of SCF by LCF in deep convective clouds than in warm shallow clouds (Table 3). However, cloud fraction and domain-average LWC are smaller in the low-aerosol run in DEEP than in SHALLOW, favoring more absorption of LW emitted from surface in SHALLOW. In addition to cloud mass and fraction, temperature at the top of liquid cloud affects outgoing LW and the top of liquid cloud is higher in both the high- and low-aerosol runs in DEEP than in SHALLOW (Fig. 3a and e). As shown by Jensen et al. (1994), LCF at the top of the atmosphere is roughly proportional to the difference in temperature between cloud top and the surface for the identical cloud optical depth. As shown in Fig. 3a, liquid-cloud top reaches around $10 \mathrm{~km}$ where average temperature is $232 \mathrm{~K}$ in DEEP. In SHALLOW, liquid-cloud top reaches just around $1 \mathrm{~km}$ (Fig. 3e) where average temperature is $286 \mathrm{~K}$. At the surface, the average 
a

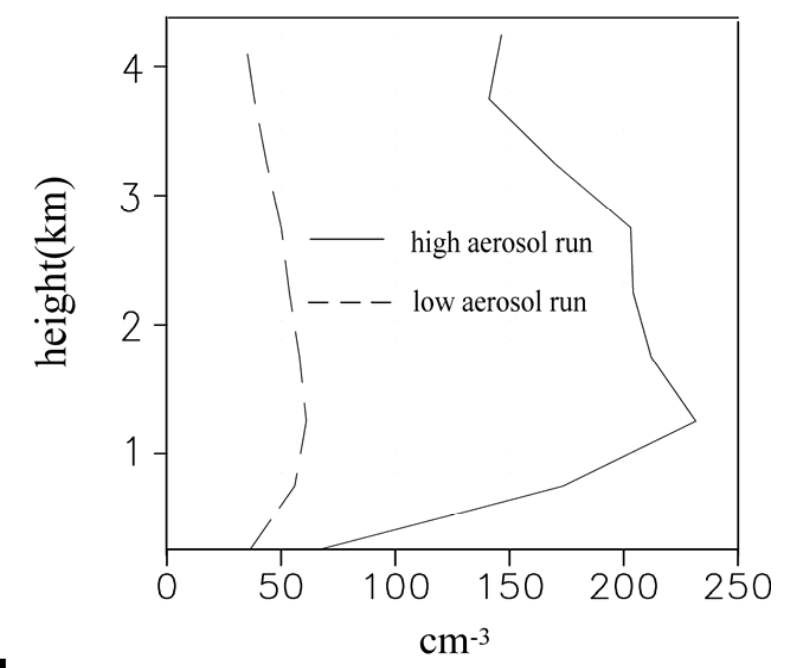

b

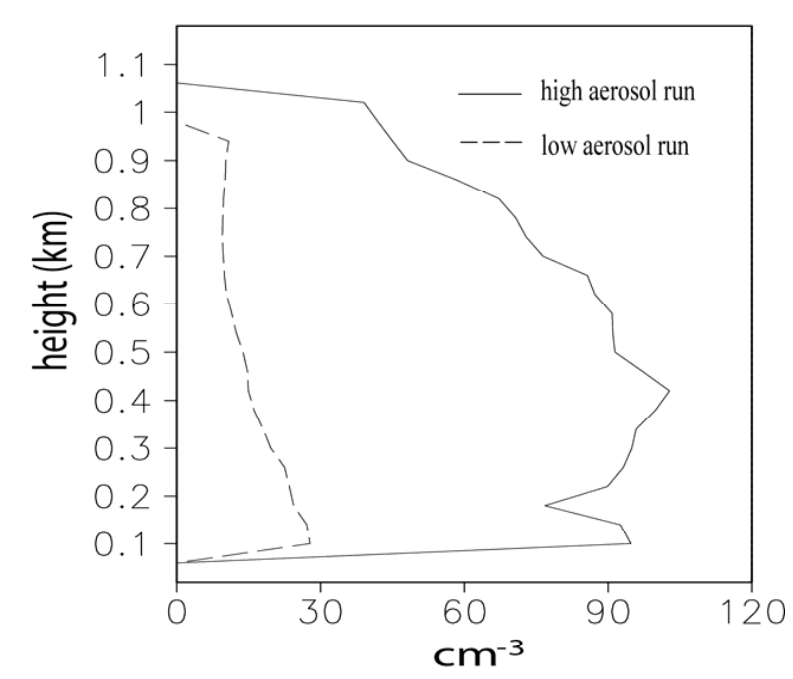

Fig. 4. Vertical distribution of in-cloud average $\mathrm{CDNC}\left(\mathrm{cm}^{-3}\right)$ (a) in DEEP and (b) in SHALLOW, conditionally averaged over grid points of non-zero droplet nucleation rate below freezing level. The bottom of each figure corresponds to the lowest grid point of the atmosphere which is 250 (20) $\mathrm{m}$ for DEEP (SHALLOW).

temperature is $295 \mathrm{~K}$ in DEEP and $288 \mathrm{~K}$ in SHALLOW. Hence, larger vertical extent of liquid cloud leading to larger temperature difference between liquid-cloud top and the surface in DEEP than in SHALLOW contributes to larger offset of SCF by LCF in tandem with increased liquid mass at high aerosol. The effect of this larger temperature difference on LCF outweighs the effect of decreased liquid mass and cloud fraction on LCF, leading to larger offset of SCF by LCF in liquid clouds in DEEP than in SHALLOW at low aerosol.
In addition to LWC, ice-water content (IWC) plays a role in radiation in DEEP, which is absent in SHALLOW. As indicated by Liou (2005), ice clouds play an important role in the trapping of LW from the surface and their high altitude enhances the reduction of outgoing LW. Their higher altitude than that of liquid clouds, as shown in Fig. $3 \mathrm{a}$ and b, increases LCF and thereby the offset of SCF by LCF at the top as compared to those when only liquid clouds are considered. The comparison of DEEP to DEEP (LIQ) (Table 1) for each of the high- and low-aerosol runs indicates that ice clouds play as important roles as liquid clouds for larger offset of SCF by LCF in DEEP than in SHALLOW at the top of the atmosphere.

Significant differences are observed in effective sizes of cloud liquid, liquid content, and ice content between the high- and low-aerosol runs in DEEP (Figs. 2a, 3a, and 3b). The high-aerosol run has higher liquid content and smaller liquid sizes than the low-aerosol run, and the ice content is also larger in the high-aerosol run. Cloud liquid is $\sim 5$ times greater around $4 \mathrm{~km}$ in the high-aerosol run. Cloud ice content is $\sim 4$ times larger at high aerosol around $10 \mathrm{~km}$. Larger cloud water content at high aerosol is due to increased condensation and deposition. Domain-averaged cumulative condensation and deposition are larger in the high-aerosol run than in the low-aerosol run by $25.04 \mathrm{~mm}$ and $8.30 \mathrm{~mm}$, respectively. The domain-averaged cumulative value (denoted by $<>$ ) of any variable (denoted by $A$ ) in this study is calculated using the following formulation:

$<A>=\frac{1}{L x} \iiint \rho_{a} A d x d z d t$

where $L x$ is the domain horizontal lengths, which are 168 and $26 \mathrm{~km}$ for DEEP and SHALLOW, respectively, and $\rho_{a}$ is the air density. The smaller size of cloud liquid is due to larger cloud droplet number concentration (CDNC) in the high-aerosol run. The high-aerosol run shows 3-5 times larger CDNC below freezing level where most differences in droplet size are observed (Fig. 4a). The time- and domainaverage cloud liquid at high aerosol in SHALLOW is larger than that at low aerosol by $\sim 53 \%$, much smaller than $320 \%$ increase shown in the high-aerosol run in DEEP (Fig. 3a and e). CDNC is also larger at high aerosol than at low aerosol in SHALLOW. This leads to the smaller size of cloud liquid at high aerosol than at low aerosol in SHALLOW (Fig. 4b). The smaller differences in cloud-liquid content in SHALLOW are due to smaller increases in condensation in the high-aerosol run than those in DEEP. Domain-average cumulative condensation increases in the high-aerosol run by $\sim 28 \%$ in SHALLOW, which is $\sim 7$ times smaller increase as compared to that in DEEP.

Larger cloud mass and fraction (note that averaged cloud fractions are $0.32(0.95)$ and $0.27(0.90)$ at high and low aerosols in DEEP (SHALLOW), respectively), smaller size of cloud particles at high aerosol favor larger reflection and absorption of downward SW (and more outgoing SW at the 
model top and less SW reaching the surface). Increased cloud mass and fraction cause more LW emitted from the surface to be absorbed by clouds at high aerosol, leading to smaller outgoing LW at the top and larger downward LW at the surface in the high-aerosol run than in the low-aerosol run (Tables 1 and 2). Those changes in LW offset changes in SW and the high-aerosol run in DEEP shows larger offset than in SHALLOW mainly due to larger increases in cloud mass (Fig. 3 and Table 3 ).

It should be pointed out that there are significant increases in cloud-ice content in the high-aerosol run in DEEP, contributing to more reflection and absorption of SW and LW, respectively. The comparison of DEEP to DEEP (LIQ) indicates changes in ice-particle mass accounts for a third of the offset of increased reflection of SW by increased absorption of LW at high aerosol in DEEP at the top of the atmosphere.

Increased condensation and deposition at high aerosol are due to more updraft activity as shown in Fig. 5 illustrating the updraft mass fluxes in the high- and low-aerosol runs. The increased updraft activity is linked to enhanced near-surface convergence at high aerosol, which in turn results from increased downdrafts driven by evaporation. Delayed autoconversion due to higher CDNC provides more abundant cloud liquid to be transported into unsaturated areas as the source of this increased evaporation. These feedbacks between dynamics and microphysics are described in more detail in Lee et al. (2008a) and simulated in Khain et al. (2003, 2004, 2005, 2008) and Lynn et al. (2005). Lee et al. (2008b) indicated that increases in updrafts, leading to increases in condensation and deposition, were much larger in deep convective clouds than those in shallow clouds at high aerosol as shown in Fig. 5a and b; the differences in in-cloud averaged increases of mass fluxes at high aerosol between DEEP and SHALLOW are $\sim 4$ times larger than those shown in Fig. 5a and b, indicating there is a larger relative increase in mass fluxes at high aerosol in cloud regions in DEEP than in SHALLOW. They found that increased cloud particles were transported to unsaturated areas more efficiently due to stronger convective motion at high aerosol in deep convective clouds than in shallow clouds. Hence, evaporation increase was much larger at high aerosol in deep convective clouds than in shallow clouds. Also, downdrafts with increased intensity from increased evaporation could be accelerated more as they descended to the surface at high aerosol due to deeper cloud depth providing longer path for their descent in deep convective clouds than in shallow clouds. This leads to more enhanced near-surface convergence and updrafts at high aerosol in deep clouds than in shallow clouds. The differing responses of deep and shallow clouds to increased aerosol are depicted schematically in Fig. 6 .

Maximum CAPE is $\sim 2500 \mathrm{~J} \mathrm{~kg}^{-1}$ and maximum wind shear is $\sim 0.0075 \mathrm{~s}^{-1}$ in DEEP. CAPE is the integral of parcel buoyancy from the surface to the domain top. Wind shear is the change of wind speed from a grid to a grid immediately above it, averaged over the lowest $6 \mathrm{~km}$, unless otherwise a
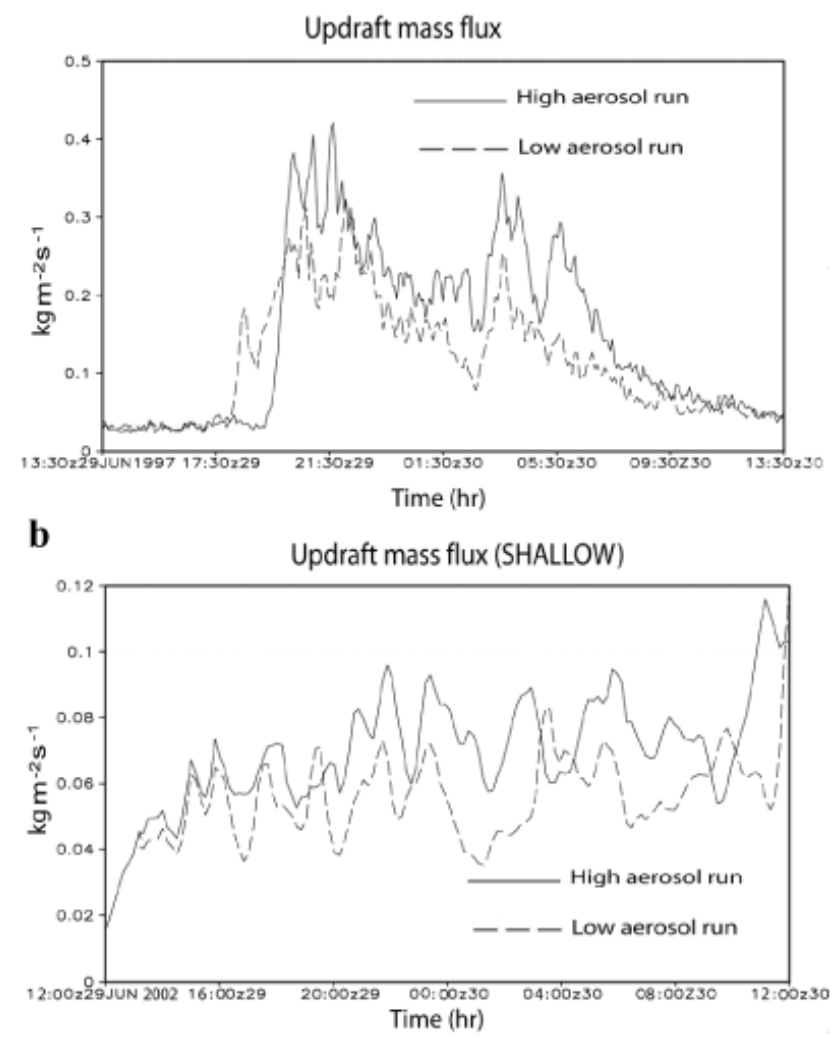

Fig. 5. Time series of domain-averaged updraft mass flux (for those whose values are above-zero) (a) in DEEP at the lowest $5 \mathrm{~km}$ and (b) in SHALLOW at the lowest $1.5 \mathrm{~km}$.

stated; Wilhelmson and Klemp (1978) showed that low-level shear below $6 \mathrm{~km}$ was more important to the development of modeled convection than upper-level shear. According to Bluestein (1993), these CAPE and shear conditions support the development of deep cumulonimbus-type clouds, as simulated in DEEP.

\subsection{Idealized stratiform clouds}

Although similar radiation inputs (at TOA and the surface) and aerosols are applied to both types of clouds in DEEP and SHALLOW, the other environmental factors may have affected differences in cloud and aerosol effects on radiation between DEEP and SHALLOW. It is ideal to keep the environmental conditions (e.g., initial condition, surface albedo, large-scale forcing and surface fluxes) to be identical for those different types of clouds to better isolate cloud and aerosol effects on radiation. However, it is unlikely to simulate different types of clouds with identical conditions, since Weisman and Klemp (1982) and Bluestein (1993) show strong dependences of cloud types on environmental factors such as CAPE and wind shear. Moreover, warm stratiform clouds develop under neutrally stratified condition in 


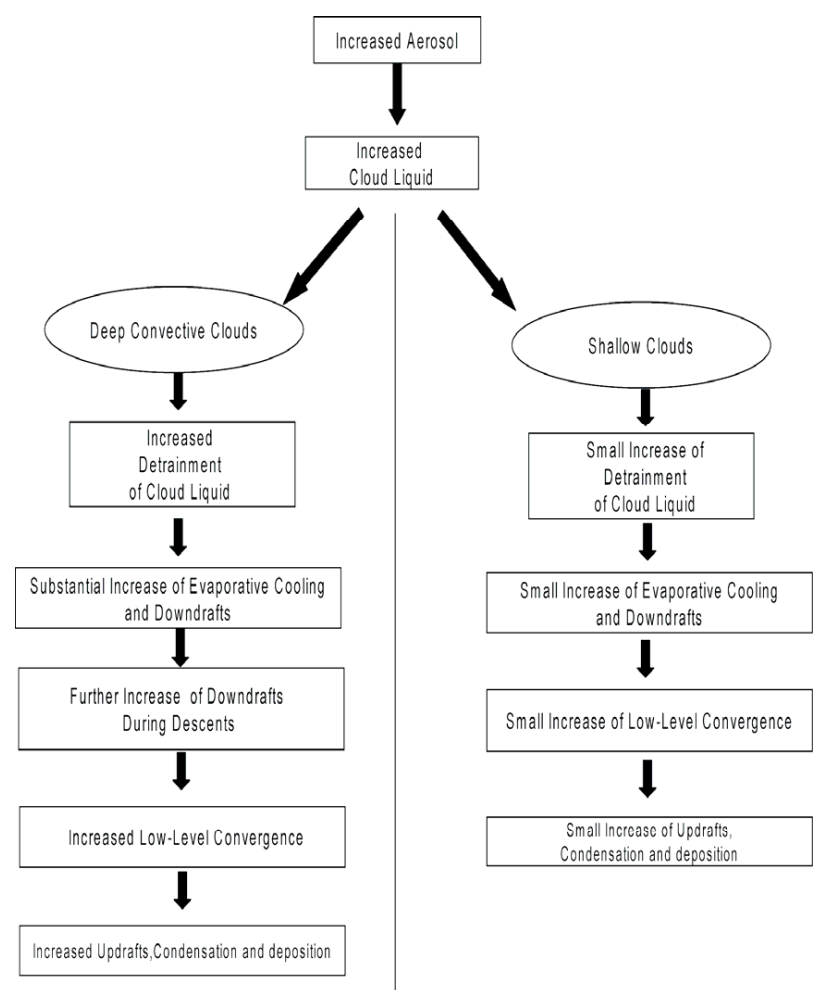

Fig. 6. Schematic diagram illustrating the differing extent of interactions between aerosols, microphysics, and dynamics in deep and shallow convection.

the planetary boundary layer (PBL) with strong inversion on its top while deep convective clouds develop under unstable conditions. Hence, it is needed to find a compromise by simulating different types of clouds while minimizing differences in environmental conditions.

To further minimize differences in environmental condition between the MCS and warm stratiform clouds, an idealized simulation of stratiform clouds (henceforth, referred to as SHALLOW (IDEAL)) at the same LST period and location on the same date in the same year as for DEEP is performed. Hence, there are no differences in radiation input at TOA and almost no differences in radiation input at the surface between DEEP and SHALLOW (IDEAL). Also, there are no differences in background aerosols and surface albedo between DEEP and SHALLOW (IDEAL). To generate the idealized stratiform clouds, the same initial condition, large-scale forcing, and surface fluxes as for DEEP are used for SHALLOW (IDEAL) except for larger-scale temperature forcing to contribute to the further minimization of differences in environmental conditions. For SHALLOW (IDEAL), positive large-scale temperature forcing is applied around the freezing-level as shown in Fig. 7b, whereas negative temperature forcing is applied around the freezing-level for DEEP as shown in Fig. 7a. The positive temperature forcing around the freezing-level favors the formation of in-
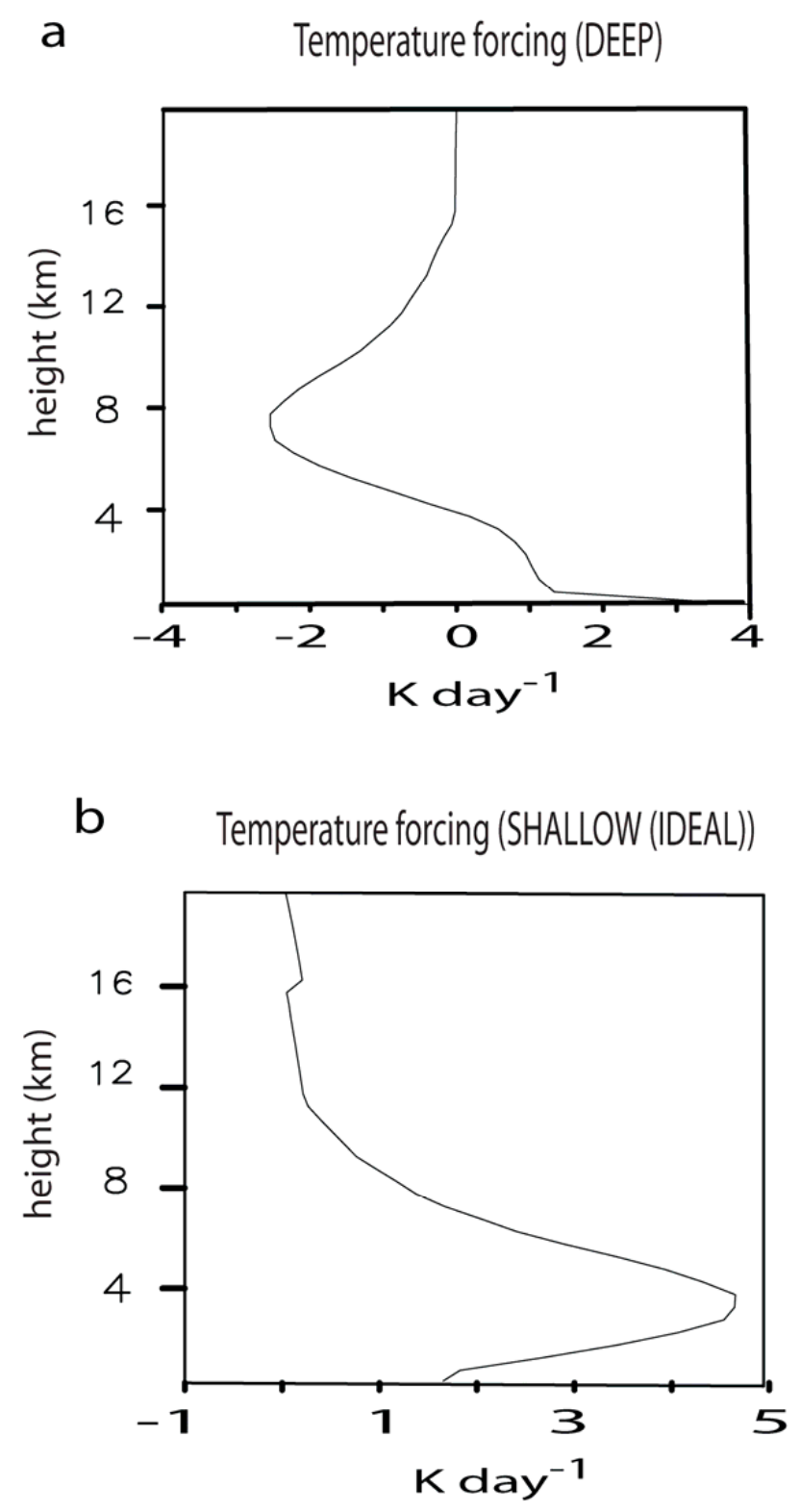

Fig. 7. Time- and domain-averaged vertical distribution of potential temperature large-scale forcing $\left(\mathrm{K} \mathrm{day}^{-1}\right)$ for (a) DEEP and (b) SHALLOW (IDEAL). The bottom of each figure corresponds to the lowest grid point of the atmosphere which is 250 (20) $\mathrm{m}$ for DEEP (SHALLOW).

version layer and thus the formation of shallow warm stratiform clouds. This generates stratiform clouds developing under more similar environment to that in DEEP than those in SHALLOW, although the inversion layer from the positive temperature forcing leads to lower maximum CAPE $(\sim 300 \mathrm{~J} \mathrm{~kg})$ than that $\left(\sim 2500 \mathrm{~J} \mathrm{~kg}^{-1}\right)$ in DEEP. The high- and low-aerosol runs for SHALLOW (IDEAL) are performed using the same aerosol profiles as for the high- and low-aerosol 
Table 4. Time- and area-averaged TOA SCF, LCF, and CRF $\left(\mathrm{W} \mathrm{m}^{-2}\right)$ for SHALLOW (IDEAL), DEEP (CU) and DEEP (LOW-CU).

\begin{tabular}{|c|c|c|c|c|c|c|c|c|c|}
\hline \multicolumn{10}{|c|}{ TOA $\left(\mathrm{W} \mathrm{m}^{-2}\right)$} \\
\hline & \multicolumn{3}{|c|}{$\mathrm{SCF}$} & \multicolumn{3}{|c|}{ LCF } & \multicolumn{3}{|c|}{ CRF } \\
\hline & $\begin{array}{l}\text { SHALLOW } \\
\text { (IDEAL) }\end{array}$ & $\begin{array}{c}\text { DEEP } \\
(\mathrm{CU})\end{array}$ & $\begin{array}{c}\text { DEEP } \\
\text { (LOW-CU) }\end{array}$ & $\begin{array}{l}\text { SHALLOW } \\
\text { (IDEAL) }\end{array}$ & $\begin{array}{l}\text { DEEP } \\
(\mathrm{CU})\end{array}$ & $\begin{array}{c}\text { DEEP } \\
\text { (LOW-CU) }\end{array}$ & $\begin{array}{l}\text { SHALLOW } \\
\text { (IDEAL) }\end{array}$ & $\begin{array}{c}\text { DEEP } \\
(\mathrm{CU})\end{array}$ & $\begin{array}{c}\text { DEEP } \\
\text { (LOW-CU) }\end{array}$ \\
\hline Low aerosol & -20.21 & -15.43 & -25.02 & 3.64 & 5.24 & 6.26 & -16.57 & -10.19 & -18.76 \\
\hline High aerosol & -40.01 & -39.45 & -43.79 & 4.60 & 10.65 & 9.63 & -35.41 & -28.80 & -34.16 \\
\hline $\begin{array}{l}\text { Difference } \\
\text { (high-low) }\end{array}$ & -19.80 & -24.02 & -18.77 & 0.96 & 5.41 & 3.37 & -18.84 & -18.61 & -15.40 \\
\hline
\end{tabular}

runs, respectively, in DEEP. The same domain size and grid horizontal and vertical lengths as in SHALLOW are used for SHALLOW (IDEAL).

Time- and domain-averaged LWC is 0.0030 and $0.0020 \mathrm{~g} \mathrm{~m}^{-3}$ in the high- and low-aerosol runs, respectively, in SHALLOW (IDEAL). Averaged cloud fractions calculated in the same manner as for DEEP and SHALLOW are 0.98 and 0.95 at high and low aerosol, respectively. Although LWC and cloud faction in SHALLOW (IDEAL) are larger than those in DEEP in both the high- and low-aerosol runs, favoring more absorption of LW from the surface in SHALLOW (IDEAL), just $11 \%(18 \%)$ of SCF is counterbalanced in the high-aerosol run (low-aerosol run) in SHALLOW (IDEAL). Note that $45 \%(81 \%)$ of SCF is counterbalanced by LCF in the high-aerosol run (low-aerosol run) in DEEP at TOA (Tables 3 and 4) (DEEP (CU) and DEEP (LOW-CU) in Table 4 will be described in the following section). This is because the difference in temperature between cloud top and the surface is much smaller in SHALLOW (IDEAL) than in DEEP. The cloud-top in SHALLOW (IDEAL) reaches just around $2 \mathrm{~km}$ where average temperature is $\sim 293 \mathrm{~K}$ and average surface temperature is nearly the same $(\sim 295 \mathrm{~K})$ in both DEEP and SHALLOW (IDEAL). Note that deep convective clouds in DEEP reaches more than $10 \mathrm{~km}$ where average temperature is smaller than $232 \mathrm{~K}$.

Due to substantially less detrainment of cloud liquid and limited vertical extent of shallow clouds in SHALLOW (IDEAL), differences in evaporative cooling, convergence, and updrafts between high and low aerosol cases reduce as compared to those in DEEP as depicted in Fig. 6. This leads to cloud-liquid increase of $\sim 50 \%$ in the high-aerosol run, $\sim 6$ times smaller increase than that shown in DEEP. This in turn leads to much smaller offset of increased negative SCF by increased LCF in SHALLOW (IDEAL) than that in DEEP. Just $5 \%$ of increased negative SCF is offset by increased LCF in SHALLOW (IDEAL), whereas DEEP shows the offset of as much as $28 \%$ at TOA.

Analysis here shows that differences in responses of radiation to clouds and aerosols between SHALLOW and DEEP are similar to those between SHALLOW (IDEAL) and DEEP. This is despite different environmental conditions between SHALLOW and SHALLOW (IDEAL). SHALLOW and SHALLOW (IDEAL) adopt the different initial and large-scale humidity and temperature conditions, surface fluxes, and surface albedo although they both have the inversion layer and the similar low wind shear (based on the wind variation from the surface to the cloud-top) and CAPE, favorable for the development of stratiform clouds; the maximum wind shear and CAPE during high- and low-aerosol simulations are $\sim 0.0004 \mathrm{~s}^{-1}$ and $\sim 300 \mathrm{~J} \mathrm{~kg}^{-1}$, respectively, for both SHALLOW and SHALLOW (IDEAL). This indicates that different responses of radiation between deep clouds and low-level shallow clouds are fairly robust to surface conditions and overall atmospheric temperature and humidity conditions of stratiform clouds. The presence of the inversion layer in the cases of shallow clouds (leading to low CAPE and the formation of stratiform clouds with smaller cloud depth and lower cloud-top height than those in deep convective clouds) plays a key role in those different responses between deep convective and stratiform clouds.

\subsection{Idealized convective clouds}

The above analyses of radiation for the deep MCS and stratiform clouds imply that the modulation of LCF can even vary with types of convective clouds with different cloudtop height and cloud depth. To examine the sensitivity of modulation of LCF to types of convective clouds, two sets of additional simulations of idealized convective clouds are performed. Each set of simulations is composed of the highand low-aerosol runs.

Updrafts play an important role in cloud depth and cloudtop height of convective clouds; stronger updrafts carry cloud particles higher. Updraft strength is partly determined by CAPE (Weisman and Klemp, 1982). To generate convective clouds with different cloud-top height and cloud depth, different CAPE levels are applied to those additional sets of simulations. Comparisons among DEEP and these additional simulations elucidate the dependence of the effects of clouds and aerosols on radiation on types of convective clouds. To better isolate this dependence, differences in environmental conditions among three cases of convective clouds 

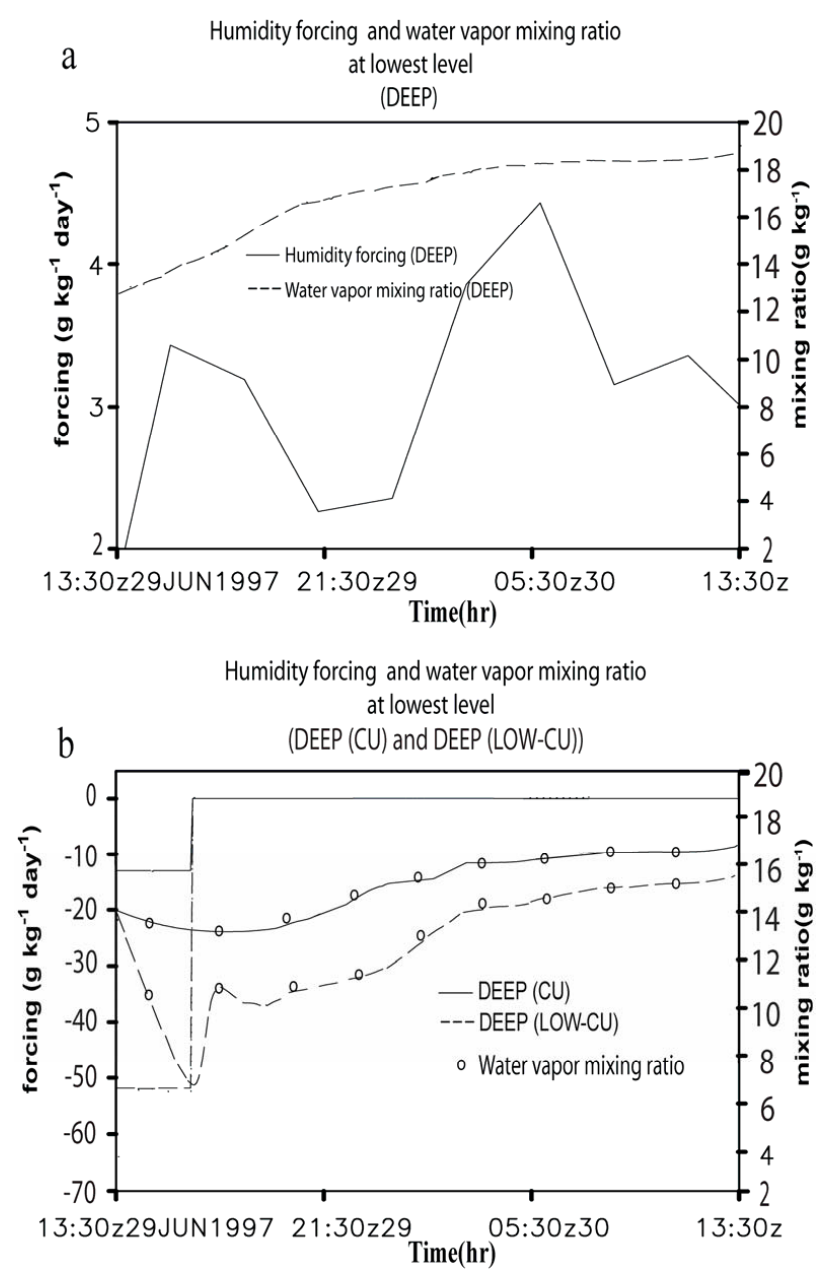

Fig. 8. Time series of humidity large-scale forcing and areaaveraged water vapor mixing ratio at the lowest level of the atmosphere (a) for DEEP and (b) for DEEP (CU) and DEEP (LOW-CU).

in this study need to be minimized. For the minimization, only initial humidity fields and humidity forcing at the lowest level are imposed differently to generate different CAPE levels. This is because CAPE shows strong sensitivity to the lowest-level humidity partly controlled by surface fluxes. Except for the lowest-level humidity, the identical environment and aerosol conditions and model setup of the highaerosol run (the low-aerosol run) in DEEP are applied to the high-aerosol run (the low-aerosol run) in these additional simulations. In the first set of simulations, moderate CAPE value of $\sim 1500 \mathrm{~J} \mathrm{~kg}^{-1}$ is applied, which is to support the formation of cumulus clouds according to Bluestein (1993). In the second of set of simulations, low CAPE value of $\sim 500 \mathrm{~J} \mathrm{~kg}^{-1}$ is applied, which is to support the formation of low-level cumulus clouds according to Bluestein (1993). Henceforth, the first and second sets of simulations are referred to as DEEP (CU) and DEEP (LOW-CU), respectively.
Figure 8 depicts the time series of humidity large-scale forcing and area-averaged water vapor mixing ratio at the lowest level of the atmosphere for DEEP, DEEP (CU), and DEEP (LOW-CU). The negative forcing at the lowest level in DEEP (CU) and DEEP (LOW-CU) lowers water vapor at the lowest level by offsetting the effect of strong surface positive moisture flux on water vapor at the lowest level prior to 16:40 UTC on 29 June; the negative forcing (positive surface moisture flux) acts to decrease (increase) the waver vapor at the lowest level. Around 16:40 UTC, the humidity forcing at the lowest level becomes zero losing its ability to offset the effect of strong positive surface moisture flux. Hence, the water-vapor-increase effect of the surface moisture flux begins to predominantly control the lowest-level water vapor. This causes vapor mixing ratio at the lowest level to begin to rise around 16:40 UTC. Note that identical surface fluxes are prescribed in DEEP, DEEP (CU), and DEEP (LOW-CU). Hence, after the humidity forcing becomes zero, the mixing ratio in DEEP (CU) and DEEP (LOW-CU) stabilizes to a value lower than that in DEEP around 16:30 UTC (Fig. $8 \mathrm{a}$ and b). The maximum CAPEs are $\sim 1500 \mathrm{~J} \mathrm{~kg}^{-1}$ and $\sim 500 \mathrm{~J} \mathrm{~kg}^{-1}$ for DEEP (CU) and DEEP (LOW-CU), respectively, as intended. Note that the maximum CAPE in DEEP is $\sim 2500 \mathrm{~J} \mathrm{~kg}^{-1}$ where cumulonimbus-type clouds are dominant. With lower CAPE in DEEP (CU) than in DEEP, cumulus-type clouds are as dominant as cumulonimbus-type clouds in DEEP (CU). With the lowest CAPE among three cases of convective clouds, lower cumulus clouds as compared to those in DEEP (CU) are dominant in DEEP (LOW$\mathrm{CU})$. Lower CAPEs in DEEP (CU) and DEEP (LOW-CU) than in DEEP lead to lower cloud depth and cloud-top height as can be seen in the comparison between Figs. 3 and 9. Figure 9 depicts vertical profiles of time- and domain-averaged cloud liquid and cloud ice content in DEEP (CU) and DEEP (LOW-CU).

Time- and domain-averaged cloud mass (cloud liquid+cloud ice) is 0.0027 (0.0010) and $0.0028(0.0017) \mathrm{g} \mathrm{m}^{-3}$ at high (low) aerosol in DEEP (CU) and DEEP (LOW-CU), respectively. Averaged cloud fractions calculated in the same manner as for DEEP are $0.40(0.38)$ and $0.51(0.50)$ at high (low) aerosol in DEEP (CU) and DEEP (LOW-CU), respectively. Although LWC and cloud faction in DEEP (CU) and DEEP (LOW-CU) are larger than those in DEEP in both the high- and low-aerosol runs, favoring more absorption of LW from the surface in DEEP (CU) and DEEP (LOW-CU), 27\% $(34 \%)$ and $22 \%$ (25\%) of SCF is counterbalanced in the highaerosol run (the low-aerosol run) in DEEP (CU) and DEEP (LOW-CU), respectively, while $45 \%$ (81\%) of SCF is counterbalanced by LCF in the high-aerosol run (the low-aerosol run) in DEEP as shown in Tables 3 and 4.

Increasing cloud fraction and mass with varying dominant cloud types from cumulonimbus in DEEP to cumulonimbus and cumulus in DEEP (CU) contribute to increases in negative SCF. However, due to lowering cloud-top height, LCF decreases with this variation of cloud types, leading to the 
a
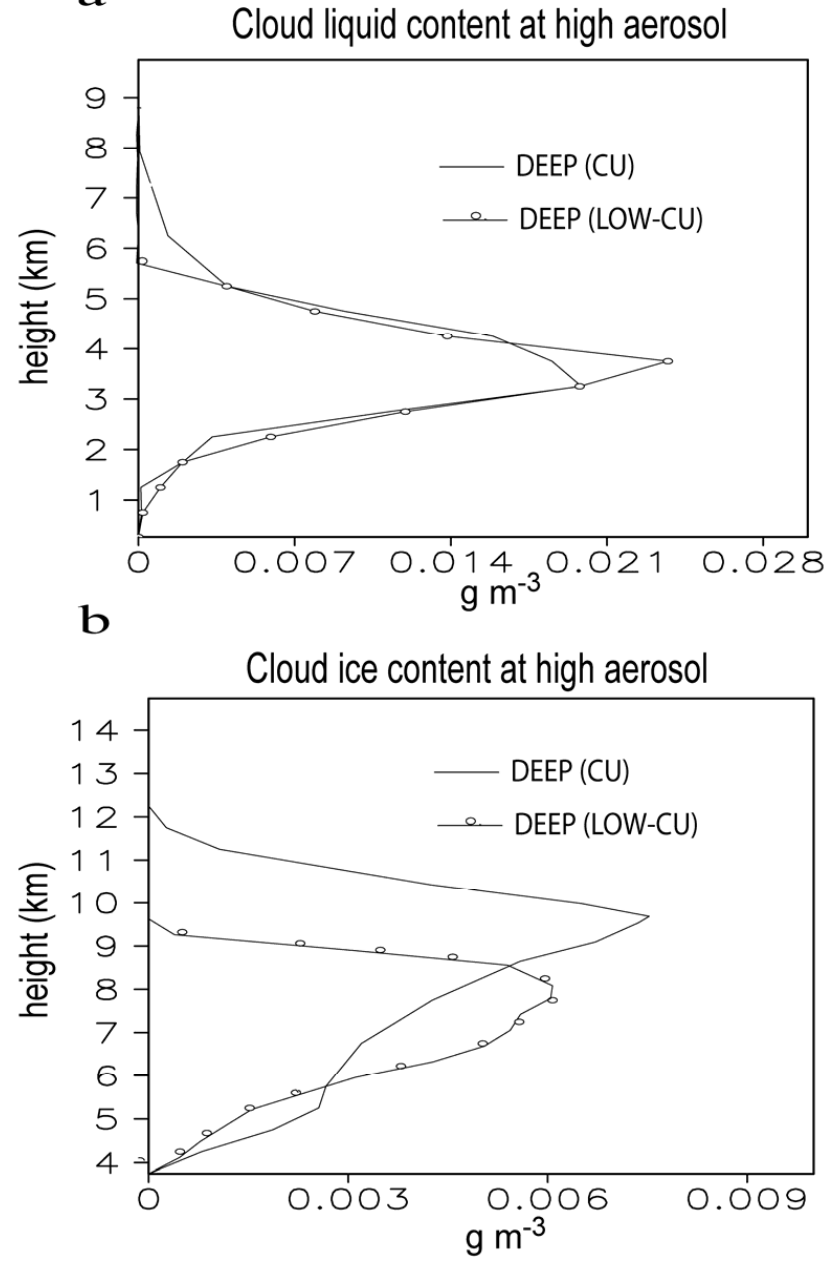

Fig. 9. Vertical profiles of time- and domain-averaged contents of (a) cloud liquid and (b) cloud ice in the high-aerosol runs for DEEP (CU) and DEEP (LOW-CU). The bottom of figure (a) corresponds to the lowest grid point of the atmosphere which is $250 \mathrm{~m}$ for DEEP.

smaller offset of SCF by LCF in DEEP (CU) than DEEP (Tables 3 and 4). Transition of dominant cloud type from cumulonimbus and cumulus in DEEP (CU) to low-level cumulus in DEEP (LOW-CU) also accompanies increasing cloud fraction and mass, contributing to increases in negative SCF. LCF also increases with this transition at low aerosol (while LCF decreases with this transition at high aerosol). However, due to lowering cloud-top height with this transition, increases in LCF are not as large as in those in negative SCF, leading to smaller offset of SCF by LCF in DEEP (LOW-CU) than in DEEP (CU) at low aerosol (Tables 3 and 4).

Smaller vertical extent of clouds in DEEP (CU) and DEEP (LOW-CU) than in DEEP leads to smaller differences in evaporative cooling, convergence and updrafts between high and low aerosol cases (see Fig. 10 for the updrafts differences). This leads to $\sim 2$ and $\sim 5$ times smaller percentage increases in cloud mass in DEEP (CU) and DEEP (LOW-

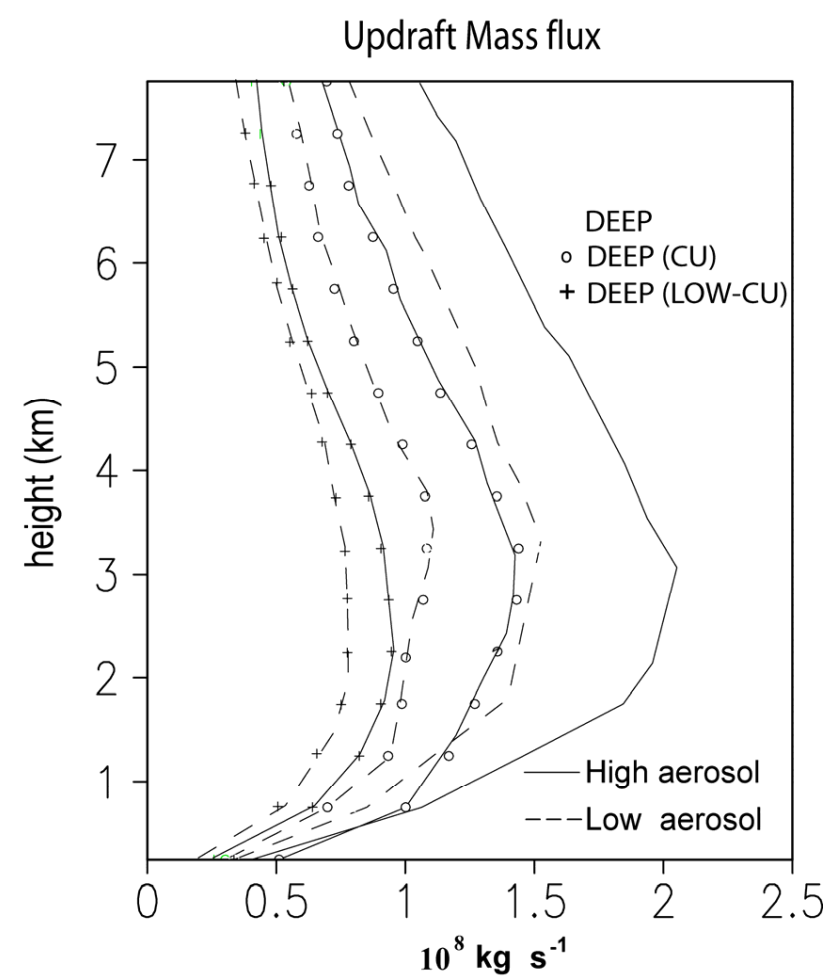

Fig. 10. Vertical profiles of time-averaged updraft mass flux (for those whose values are above-zero) for DEEP, DEEP (CU) and DEEP (LOW-CU). The bottom of the figure corresponds to the lowest grid point of the atmosphere which is $250 \mathrm{~m}$ for DEEP.

$\mathrm{CU})$, respectively, than in DEEP at high aerosol. This, in turn, leads to 23 (18)\% of increased negative SCF offset by increased LCF in DEEP (CU) (DEEP (LOW-CU)), whereas DEEP shows the offset of as much as $28 \%$ at TOA. The smaller vertical extent of clouds leads to smaller offset of increased negative SCF by increased LCF at high aerosol in DEEP (LOW-CU) than in DEEP (CU).

Simulations for stratiform and convective clouds in this study demonstrate that cloud-top height and cloud depth play a critical role in the offset of SCF by LCF and offset of increasing negative SCF by increasing LCF at high aerosol.

\subsection{Effects of parameters of microphysics parameteri- zation}

The sensitivity of results to parameters used for parameterizations of microphysical processes and size distributions which can affect the mass and number of cloud liquid and cloud ice and thus radiation needs to be examined. For the examination of the sensitivity to some of selected parameters, simulations in DEEP are repeated by varying the values of those parameters. Selected parameters are associated with the fall speed of ice crystals, the conversion of rimed snow to hail, size distributions of precipitable hydrometeors (i.e., 
snow, hail, and rain), and crystal habits for collection and optical properties.

The repeated simulations show that model results can be considered robust to the variation of parameters used in the fall speed of ice crystals (i.e., coefficients in the fall-speed power law), in the conversion of rimed snow to hail (i.e., the threshold mixing ratio of snow mass), in the size distribution of precipitable hydrometeors (i.e., the intercept parameter). In those additional simulations, the coefficients in the fall-speed power law vary from the lowest value to the highest value estimated by Khvorostyanov and Curry (2002). The threshold mixing ratio of snow mass decreases and increases from a value used in this study $\left(0.5 \mathrm{~g} \mathrm{~m}^{-3}\right)$ by a factor of 10 . The intercept parameter varies from $8 \times 10^{5}$ to $8 \times 10^{7}$ for rain, from $3 \times 10^{2}$ to $3 \times 10^{8}$ for snow, and from $4 \times 10^{2}$ to $4 \times 10^{8} \mathrm{~m}^{-4}$ for hail. The range of the variation of the intercept parameters is based on the estimated range by Tong and Xue (2008), Gilmore et al. (2004), and McFarquhar and Black (2004). Those variations lead to less than $\sim 10 \%$ changes in the percentage offset of SCF by LCF in each of the high- and low-aerosol runs and less than $\sim 5 \%$ changes in the percentage offset of the increased SCF by increased LCF at high aerosol, as compared to those shown in Table 1. These variations in the offsets are much smaller than those between stratiform clouds and deep convective clouds.

As can be seen in Fig. 3b, the large portion of mass of cloud ice is concentrated around or above the level of homogeneous freezing $(\sim 10 \mathrm{~km})$ where the conversion of cloud ice to precipitable snow is known to be very inefficient due to the absence of liquid-phase particles. Hence, although we assumed the collection efficiency of 1 for collisions between cloud ice and liquid-phase particles, just $\sim 5 \%$ of the ice formed by deposition was converted into snow in this study. Different crystal habits lead to different collection efficiencies (Pruppacher and Klett, 1978). This indicates that different crystal habits lead to different removal of cloud ice through precipitation as snow, which in turn can change the mass of cloud ice and thus radiative properties of deep clouds. However, the low conversion efficiency of cloud ice, which is $\sim 5 \%$, even with the collection efficiency of 1 demonstrates that there will be negligible changes in the mass of cloud ice with different crystal habits assumed. If we assume a crystal habit having the efficiency of 0.1 or lower (corresponding to around the lower end of the efficiency variation), it is expected that $\sim 0.5 \%$ or lower of cloud ice is converted into snow. This brings only $\sim 4.9 \%$ or lower change to the mass of cloud ice simulated in this study. This indicates that results here are not likely to depend on changes in the mass of cloud ice induced by different conversion of ice crystals to snow due to the variation of an assumed crystal habit for collection processes.

The dependence of crystal optical properties on the crystal habit is a function of the aspect ratio of ice particles ( $\mathrm{Fu}$, 2008); the difference in the crystal optical properties is proportional to that in the aspect ratio characterizing the crystal habit. This study assumed the columnar shape of ice crystals for the characterization of the optical properties and thus calculation of radiative fluxes, following Phillips et al. (2007). The columnar shape has an aspect ratio of $\sim 0.3-0.5$, which corresponds to the lower range of aspect ratio of ice particles. $\mathrm{Fu}(2008)$ showed the increase in reflected solar fluxes by cirrus clouds by $\sim 10 \%$ when the crystal habit changes from the columnar shape to the plate or dendrites having aspect ratio around $0.7-1.0$, corresponding to the upper range of the aspect ratio. Wendisch et al. (2007) showed that that change in the habit leads to $\sim 14-20 \%$ increases in LCF. These changes in SCF and LCF bring only less than 5\% change to the percentage offset of SCF by LCF in each of the high- and lowaerosols runs and to the offset of varying SCF by varying LCF between the high- and low-aerosol runs shown in Table 1 . This demonstrates that the qualitative nature of results of this study does not depend on crystal optical properties varying with the crystal habit.

\subsection{Role of CCN and IN}

In this study, $\mathrm{CCN}$ and IN are varied simultaneously between the high- and low-aerosol runs in DEEP, which makes it difficult to separate the effects of CCN from those of IN and vice versa. However, as shown in Lee et al. (2008a), the mechanism producing stronger updrafts is triggered by the increased evaporation of cloud liquid at high aerosol. They showed that the role of ice particles in triggering the mechanism was negligible as compared to that of liquid particles (see Sect. 4.3 and 4.4 in Lee et al. (2008a) for more detail). Also, as can be seen in Fig. 3b, large portion of mass of cloud ice is concentrated around or above the level of homogeneous freezing $(\sim 10 \mathrm{~km})$ where it is found that homogeneous freezing of haze and droplet particles (formed on $\mathrm{CCN}$ particles) accounts for most of cloud-ice number. Hence, increased $\mathrm{CCN}$ not only induces the stronger updrafts by increasing cloud-liquid evaporation but also contributes to most of increases in the number of ice particles around and above the homogeneous freezing level. The increased updrafts increase condensation and deposition and the large portion of the deposition occurs on the ice particles formed by homogeneous nucleation. Hence, it is likely that the qualitative nature of results of this study does not depend on IN variation. To confirm this, simulations in DEEP are repeated with no variation of aerosols acting as $\mathrm{CCN}$ but with the 10 -fold variation of aerosols acting as IN between the high- and low-aerosol runs. These simulations show that $2 \%$ of the increased negative SCF is offset by increased LCF at high aerosol. This offset is $\sim$ one order of magnitude smaller than those shown in simulations with both of the $\mathrm{CCN}$ and IN variations considered. However, another set of repeated simulations only with CCN variation (with no variation of IN) shows the offset of $\sim 25 \%$. Hence, these repeated simulations demonstrate that the results here are strongly sensitive to $\mathrm{CCN}$ variation and their dependence on IN variation is negligible. 


\section{Summary and discussion}

Cloud and aerosol effects on radiation in a deep MCS (DEEP) and warm stratocumulus clouds (SHALLOW) were investigated using double-moment bulk microphysics. Aerosol mass, CDNC, cloud-ice number concentration, and cloud particle size were predicted. For the nucleation of cloud particles, the chemical composition, size spectrum, and number concentration of aerosols were considered.

In SHALLOW, less than $20 \%$ of SCF is offset by LCF, whereas, in DEEP, the offset is $45 \%$ at high aerosol and as much as $81 \%$ at low aerosol at the top of the atmosphere. It is notable that ice clouds contributed to the offset as much as liquid clouds in DEEP. Ramanathan et al. (1989) also found that SCF was substantially counterbalanced by the reduction of outgoing LW in deep convective regions: (i) the tropical Pacific and Indian oceans surrounding Indonesia and the Pacific ITCZ north of the equator; (ii) the monsoon region in Central Africa and the northern third of South America; and (iii) the mid-latitude storm tracks in the Pacific and Atlantic oceans. The counterbalance is most significant in tropical convective regions where the reduction of outgoing LW nearly cancelled SW cloud forcing. They also found cirrus in those regions provided a significant contribution to the reduction of outgoing LW as diagnosed here. However, the reduction of outgoing LW relative to increases in outgoing SW due to clouds in the regions of stratiform clouds is not as significant as in deep convective regions. Hence, their study indicates that deep convective clouds affect radiation quite differently in terms of the modulation of LW as compared to shallow stratus- or stratocumulus-type clouds as simulated in this study.

An additional set of idealized simulations of warm stratiform clouds (SHALLOW (IDEAL)) with the similar environmental conditions (except for the CAPE level due to the presence of the inversion layer imposed to generate the shallow clouds) to those in DEEP was carried out. This was to isolate better the mechanisms leading to differences in cloud and aerosol effects on radiation between deep convective clouds and warm stratiform clouds. This set of simulations showed that differences in cloud-top height played a critical role in differences in the offset of SCF by LCF between deep convective clouds and warm stratiform clouds. This dependence of the relative magnitude of LCF to SCF on cloudtop height indicates changing environmental conditions due to climate changes may impact the global offset of SCF by LCF as briefly mentioned in Ramanathan et al. (1989). As an example, increases in temperature around the Earth's surface due to increases in green house gases can increase the surface humidity, and, thereby, CAPE; the Clausius-Clapeyron equation indicates that saturation water-vapor pressure increases exponentially with increasing temperature. As indicated in Weisman and Klemp (1982) and Bluestein (1993) and simulated in DEEP (CU) and DEEP (LOW-CU), CAPE plays an important role in the determination of cloud-top height.
This is because CAPE basically determines the intensity of updrafts (and thus of the convection). High (low) CAPE generally leads to high (low) updrafts, increasing (reducing) vertical transport of hydrometeors and, thus, cloud-top height. This relation between CAPE and cloud-top height was simulated in Lee et al. (2008b). Lee et al. (2008b) showed the transition of the cloud type from high-level cumulonimbus to low-level cumulus to warm stratiform clouds with decreasing CAPE caused by decreasing surface humidity. Thus, it is expected that the offset of SCF by LCF can be larger with increasing green house gases based on the comparisons of radiation among DEEP, DEEP (CU), and DEEP (LOW-CU) where CAPE (and thus cloud-top height and the offset) increased with the increased surface humidity. The evaluation of this changing offset can be critical to the assessment of the response of climate to green house gases, considering the strong sensitivity of the offset to cloud-top height simulated here.

Lohmann (2008) examined the effects of changes in greenhouse gas since industrialization on precipitation using a GCM coupled with double-moment microphysics for both convective and stratiform clouds. She reported the invigoration of convective clouds in a warmer present-day climate, leading to increased precipitation in convective regions. Hence, her results appear to support the hypothesis about the changing relation between CAPE and the convection intensity (and thus cloud-top height) with global warming, suggested above. However, the implications for largescale aspects of this study will require further study with larger-domain models which is coupled with advanced microphysics and able to resolve convective cells. Also, it should be pointed out that feedbacks between clouds and their environment for longer time period than that in this study can lead to different cloud and aerosol effects than shown here. Clouds here are simulated only for one day, which is much shorter than the time needed for a radiativeconvective equilibrium state ( $\sim 30$ days) according to Tompkins and Craig (1998). Hence, it is likely that the study here is only able to represent short-term transient behaviors of cloud and aerosol effects. This indicates the need to perform long-term simulations to draw robust climatic implications of this study.

Increases in negative SCF due to aerosol increases were found to be offset by increases in LCF more significantly in deep convective clouds than in warm shallow clouds. This was mainly due to larger increases in cloud mass (both in liquid and ice water) in deep convective clouds than in shallow clouds due to stronger feedbacks between dynamics and microphysics. SHALLOW and SHALLOW (IDEAL) showed that shallower cloud depth led to less intense feedbacks between dynamics and microphysics by providing shorter path to the surface for descending downdrafts in warm stratiform clouds than in deep convective clouds. Even among the convective clouds with different cloud depth, the offset of increased negative SCF by increased LCF at high aerosol was 
different. These indicate the critical role the cloud depth plays in aerosol-induced cloud mass and LCF changes. However, it should be pointed out that the feedbacks between microphysics and dynamics in convective clouds (DEEP, DEEP (CU), DEEP (LOW-CU)) are associated with the changes in the intensity of the gust front (i.e., the near-surface convergence), whereas they are associated with the changes in the PBL growth rate, static stability, and thus cloud-top entrainment in the shallow stratiform clouds (SHALLOW and SHALLOW (IDEAL)). Hence, while differences in those feedbacks, leading to large differences in the responses of cloud mass to aerosol changes, are basically explained by the differences in cloud depth and convective intensity between convective clouds and the shallow clouds, feedbacks in each of convective clouds and the shallow clouds are governed by fundamentally different mechanisms.

As found and suggested in Rosenfeld et al. (2008) and Seifert et al. (2005), increased cloud liquid due to increased aerosols can increase the freezing of cloud liquid when it is transported to the freezing level. This increased freezing increases the latent heat release, intensifying convection (and thus updrafts) which can lead to further increases in cloud liquid. However, Lee et al. (2008a) showed that the effect of increased freezing played a minor role in increasing updraft and cloud mass with increasing aerosols. A comparison between simulations with and without ice physics in Lee et al. (2008a) indicated that $\sim 20 \%$ of increases in updrafts and cloud mass were attributable to those increases in the freezing. In other words, most of increases in updrafts and cloud mass are due to interactions between microphysics and dynamics described in Sect. 3.2.

Cirrus clouds regularly cover $20-25 \%$ of the globe and as much as $70 \%$ over the tropics and, thus, can act as one of major modulators of global radiation budget (Liou, 1986, 2005). Houze (1993) indicated that most cirriform cloud was of the type that had its origin in the upper layers of deep, precipitation cloud systems. Ice clouds played as important roles as liquid clouds in the offset of SCF by LCF in clouds in DEEP. Large increases in ice mass with increasing aerosols in deep convective clouds simulated here implies subsequent increases in cirrus clouds detrained from parent deep convective clouds. Hence, this study suggests the feedback in deep convective clouds depicted in Fig. 6 can have a significant impact on global radiation budget by modifying thickness and coverage of cirrus clouds. Increasing ice clouds simulated here accounted for $\sim 30 \%$ of the offset of increased negative SCF by increased LCF with increasing aerosols in DEEP. Thus, increasing cirrus clouds with increasing aerosols can enhance this so-called infrared warming effects, though its global impact will depend on the relationship between aerosol distribution and deep convection, a matter this study was not able to consider. So far, most GCMs have not taken into account homogeneous freezing of droplets and haze particles for sub-grid convective clouds, playing important roles in the development of ice clouds in deep convective systems, explicitly. Also, most GCMs have mostly focused on low-level stratiform clouds for the evaluation of changes in cloud radiative forcing by aerosol increases. They have not taken into account aerosol effects on deep convection or the links of these effects on detrained cirrus. These may contribute to the large uncertainties associated with the effects of ice clouds on radiation and aerosol indirect effects.

Additional simulations were performed. Those simulations examined the sensitivity of results here to parameters in the parameterization of the ice-crystal fall speed, the threshold snow mixing ratio for the conversion of rimed snow to hail, and the size distribution of precipitable hydrometeors. They showed that results in this study were robust to those parameters. Also, it is not likely that the qualitative nature of results of this study depends on a crystal habit assumed. However, we did not carry out sensitivity tests for parameters such as those associated with autoconversion and the accretion of cloud-droplets by rain. Regarding the autoconversion of cloud-liquid to rain, it is crucial for aerosol effects on cloud systems, and there is much uncertainty about how best to represent it. Autoconversion acts as a "switch", starting coalescence when the mean size of cloud-droplets becomes larger than about 20 microns. Khairoutdinov and Kogan (2000) showed that autoconversion is a strongly increasing function of cloud-droplet mean size, consistent with observations that drizzle is absent when the average cloud-droplet size is less than about 20 microns (Pawlowska and Brenguier, 2003). So, we have correctly represented this "switching" property of autoconversion, depending on droplet size. But of course, there is experimental uncertainty about whether the switch ought to be 20 microns exactly, or some value closer to 25 microns. Concerning the accretion of cloud-droplets by rain, another uncertain parameter in our scheme is the cloud-droplet size threshold for the transition of collision efficiency from zero to unity. In nature, the collision efficiency rises gradually between zero and unity with increasing droplet size. So this cut-off size is uncertain. Despite such potential for errors in microphysical parameters in the treatment of the warm rain process, our scheme's prediction of precipitation rates compares adequately with observation (see Fig. 2 in Lee et al. (2008a) who simulated the same ARM case as in DEEP). However, it should be stressed that model results can also be sensitive to other numerous parameters (See Phillips et al. (2007) and Lin et al. (1983) for those other parameters) for which tests are not carried out or discussions are not made here. This is a cause of uncertainties of model results here. Further studies using an advanced microphysics with minimized reliance on those parameters are needed to examine these uncertainties and draw more robust conclusions.

It was found that the role of $\mathrm{CCN}$ was much more important than that of IN in the presented results here. Increased cloud-liquid evaporation, near-surface convergence and thus updrafts and ice formation around and above the level of 
homogeneous freezing determined the cloud-mass increase at high aerosol. Those processes were mostly controlled by the $\mathrm{CCN}$ increase and the IN increase played a negligible role in changing cloud mass with changing aerosols.

Lee et al. (2008a) showed that differences in the mass of ice particles (and thereby the offset of SCF by LCF) between the high- and low-aerosol runs were not significant before stronger updrafts were triggered by enhanced evaporative cooling of cloud liquid at high aerosol. The more intense feedback between updrafts and depositional heating after the development of stronger updrafts played a crucial role in the substantially increased ice mass at high aerosol. However, this does not preclude other interactions as controls on the responses of ice mass to aerosols. For example, Lohmann and Diehl (2006) indicated that the responses of ice mass to aerosol increases were significantly different with different assumptions of IN compositions of internally mixed chemical materials in mixed-phase and ice clouds; changes in ice nucleation due to increasing aerosols were significantly different for different IN chemical composition assumed. Those interactions between IN chemical compositions and responses of ice particles to aerosols deserve the further study.

Cui et al.'s (2006) study indicated that the immersion freezing was most dominant among ice-nucleation paths and less vigorous near the top of clouds at their mature stages at high aerosol due to more rapid evaporation of smaller drops in the CCOPE case. This process reduced the buoyancy at cloud top and produced stronger downdrafts flanking the updraft core of the high-aerosol clouds, cutting off the inflow within the boundary layer to lead to weaker near-surface convergence, updrafts, and cloud mass at high aerosol. Cui et al.'s (2006) study simulated clouds existing predominantly below the homogeneous freezing level whereas convective clouds in this study grow above the homogeneous freezing level except for DEEP (LOW-CU) where clouds grow to just below the homogeneous freezing level as shown in Figs. 3 and 9. Note that greater homogeneous freezing of aerosol (haze) particles and droplets contributed to larger mass of ice crystals around the top of clouds at their mature stages by boosting the buoyancy and, thereby, deposition more at high aerosol than at low aerosol in this study. Also, it should be stressed that Cui et al.'s (2006) study considered the case of weak wind shear. As simulated by Cui et al. (2006) and found by Weisman and Klemp (1982), when wind shear was weak, downdrafts destroyed the updrafts. However, in this study with moderate wind shear according to Bluestein's (1993) definition, downdraft regions were separated from updrafts cores, as shown in Fig. 8 in Lee et al. (2008a). This led to the updraft-increasing mechanisms via the developments of stronger downdrafts and thereby low-level convergence, initiating larger condensation in liquid clouds and deposition in ice clouds (mostly around and above the homogeneous freezing level) at high aerosol. Although the homogeneous freezing is absent in DEEP (LOW-
CU) as in the CCOPE case in Cui et al. (2006), these mechanisms enable the increased cloud mass in DEEP (LOW-CU) with increasing aerosols mostly by increasing condensation.

Generally, sub-grid convective clouds in climate models have been represented by cumulus parameterization which is not able to simulate microphysics explicitly. Hence, it is hard to expect that varying modulation of LCF with varying cloud-top height in convective clouds has been reasonably simulated in climate models. This is because cloudtop height is determined by the upward transportation of hydrometeors by updrafts and microphysical properties of hydrometeors affect the transportation significantly. Those properties of hydrometeors affect microphysical processes such as nucleation, phase transition, and collision having a substantial impact on latent heat distribution, cloud particle and precipitation mass, which, in turn, affect the intensity of updrafts. Also, it is hard to expect that the important roles ice clouds, associated with microphysical processes such as heterogeneous and homogeneous nucleation, play in the modulation of LCF have been reasonably simulated in climate models. Moreover, cumulus parameterization is not able to represent aerosol-induced intense interactions between microphysics and dynamics in convective clouds. Considering that increasing green house gases can lead to changes in cloud-top height and increasing aerosols can modify aerosolinduced interactions between microphysics and dynamics and thus the property of ice clouds in convective cloud systems, more accurate and explicit representation of convective clouds in climate models is needed.

The study here does not exclude the possibility of impacts of environmental conditions on cloud- and aerosol-induced infrared warming effects. Even in similar types of clouds with similar cloud-top height and cloud depth, slightly different environmental conditions such as humidity and largescale subsidence above the PBL, sea surface temperature (SST), and surface sensible and latent heat fluxes can change cloud development and aerosol-cloud interactions (Jiang et al., 2002; Ackerman et al., 2004; Guo et al., 2007; Khain et al., 2008). Hence, more case studies of various types of clouds under various environmental conditions are needed to address those impacts of environmental conditions and to better establish the generality of results here in future studies.

A given value of CAPE is not unique with respect to thermodynamic structure. For example, CAPE can be increased by increasing near-surface humidity or by increasing the middle-tropospheric lapse rate. The former approach has been used to generate the idealized CAPE variations in this paper. Increasing the CAPE in this way particularly favors increased condensate production with increasing aerosols and the subsequent interactions described here.

Use of a two-dimensional, rather than three-dimensional, cloud-system model affords substantial computational advantages but, as Phillips and Donner (2006) note, some aspects of the dynamics and microphysics in deep convection differ in two- and three-dimensional models. Phillips and 
Donner (2006) found that vertical velocities and mass fluxes in deep convective updrafts, and downdraft mass fluxes, were larger in three dimensions than two dimensions. Downdrafts play an important role in the interactions among dynamics, microphysics and radiation in deep convection described in this paper. Phillips and Donner's (2006) results suggest that this mechanism may have been underestimated in two dimensions. Conversely, Phillips and Donner (2006) also found that comparatively weak convective clouds were more numerous in two dimensions. To the extent these clouds play a role, they may be overestimated in two dimensions. Guo et al. (2007) showed that basic features of the integrations (e.g., the CDNC, LWP and effective size) were similar for two and three dimensional simulations of warm stratocumulus clouds. The results of Guo et al. (2007) suggest that responses of radiation to clouds and aerosols in warm stratiform clouds are robust to dimensionality of domain. A three-dimensional version of simulations of the same cases of deep convective system (the 1997 ARM case) and warm stratiform clouds (the 2002 case off the coast of Virginia) as simulated here has also been conducted. For this simulation, single-moment microphysics, similar to Phillips and Donner (2006), was used. The radiation in each of the highand low-aerosol run in these cases behaved similarly to that in this study. Also, the high-aerosol runs in these cases behaved relative to the low-aerosol runs similarly to the highaerosol runs in this study with similar radiation responses to aerosols. Although the microphysics is highly simplified in the three-dimensional experiments, this result suggests that the qualitative character of the results here does not depend on the dimensionality of the experiments.

As does the choice of two dimensions, the choice of resolution ( $2 \mathrm{~km}$ horizontal, $500 \mathrm{~m}$ vertical) affords substantial computational advantages. Donner et al. (1999) reported a series of test calculations with a similar cloud-system model with resolutions ranging from $500 \mathrm{~m}$ to $5 \mathrm{~km}$. They found basic features of the integrations (e.g., patterns of vertical velocity) were similar for horizontal resolutions of $2 \mathrm{~km}$ or finer for convective clouds. Phillips and Donner (2006) showed that, compared to aircraft observations of convective cores in the mid-troposphere in the Global Atmospheric Research Program (GARP) Atlantic Tropical Experiment (GATE), the frequency of vertical velocity is correctly predicted with the resolutions adopted here. Simulations in DEEP are repeated with the vertical resolution of $100 \mathrm{~m}$ to test the sensitivity of results to the vertical resolution. It is found that the principal aspects of results with the 100-m vertical resolution are similar to those with the 500-m vertical resolution. Similarly, Bryan et al. (2003) reported that basic deep convective circulation features did not change significantly when horizontal and vertical resolution increased from the order of $1 \mathrm{~km}$ to the order of $100 \mathrm{~m}$. However, Bryan et al. (2003) reported that precipitation distribution and amount, system propagation speed, cloud depth, mesoscale flow pattern, and stability structure in deep convection changed with the change in grid spacing. Due to better resolved turbulent motions with gird spacing on the order of $100 \mathrm{~m}$, there were modifications on the updraft, entrainment, and detrainment of liquid water, leading to those changes. Hence, their study suggests that the detailed turbulent structure and thereby evaporation and interactions between evaporation and dynamics can be sensitive to grid spacing, though their study also suggests that the qualitative nature of the simulations here is not expected to change with grid spacing substantially. Nevertheless, a $100 \mathrm{~m}$ grid-spacing for both horizontal and vertical resolutions would have been preferable, so as to resolve turbulence that is important especially in the boundary layer, if it were computationally feasible for our study. Shallow convection in the boundary layer is important to treat for correct prediction of cloud statistics. However, Pauluis and Garner (2005) showed that only at resolutions coarser than a few $\mathrm{km}$ does a serious bias develop in the domain-wide cloud statistics (e.g. average cloud-liquid content) due to shallow convection being unresolved. We want to add that it would also have been preferable to adopt a three-dimensional domain with the $100 \mathrm{~m}$ grid-spacing for a more realistic simulation of the shallow convection in the boundary layer. This is because the simulation of three-dimensional turbulence motions are expected to be more critical in the simulation of the shallow convection in the $100 \mathrm{~m}$ spacing than that adopted in this study.

Guo et al. (2008) found that cloud-top entrainment in the simulation of stratocumulus clouds decreased with increasing vertical resolution from $40 \mathrm{~m}$ to $5 \mathrm{~m}$. However, the sensitivity of entrainment to horizontal resolution is not significant once the horizontal resolution is finer than $100 \mathrm{~m}$. Models with resolution finer than $40 \mathrm{~m}$ (adopted in this study for stratocumulus clouds) enable more detailed simulation of entrainment and detrainment processes at cloud top, which play important roles in the evolution of shallow clouds and may not be well-represented with a model whose resolution is as coarse as that employed here. Therefore, the quantitative details of the cloud-mass changes associated with changes in aerosol concentration in SHALLOW are of limited reality. Conceding this, experiments in this study still demonstrate that interactions between microphysics and dynamics whose strength is controlled by cloud vertical extent can vary widely. These variations, which are related to stability characteristics in which clouds form, are large enough to lead to the substantial differences in cloud-mass changes with increasing aerosol concentration.

When Hong and Pan's (1996) PBL scheme (adopted in this study) is used for the horizontal resolution of $4 \mathrm{~km}$ or finer, it is reported that the PBL heights are predicted deeper by $\sim 500$ to $\sim 600 \mathrm{~m}$ as compared to those predicted by the turbulent kinetic energy scheme (Deng and Stauffer, 2006). This implies that the cloud-base height may have been overestimated in the cases of convective clouds. However, the uncertainty of the location of cloud bases nearly within the $500 \mathrm{~m}$-layer is not likely to affect the qualitative nature of 
the results here. This is because condensation and deposition from mid-level of liquid clouds (about $2-3 \mathrm{~km}$ above the bases) to the top of ice clouds play crucial roles in the determination of cloud mass and thus radiative properties of convective clouds.

The identical surface fluxes from observation are prescribed for high- and low-aerosol runs. Therefore, surface fluxes do not contribute to different near-surface convergence and radiation. In this study, we focused on how aerosols affect clouds and radiation for an identical observed net heat and moisture supplied to or removed from the domain by large-scale flow and surface fluxes. Although feedbacks from differences in clouds onto the large-scale flow and surface fluxes cannot be captured by this design, this isolates interactions between aerosols, microphysics, and local dynamics (e.g., convergence fields within the model domain with zero domain-mean average) and enables the identification of microphysics-aerosol interactions on the scale of cloud systems.

Grabowski (1999) reported the increase in the intensity of low-level convergence of deep convective clouds with increasing surface fluxes. Hence, the cloud mass is expected to be higher (lower) with higher (lower) surface fluxes through the more (less) intense near-surface convergence, leading to more (less) offset of SCF by LCF than in DEEP in each of the high- and low-aerosol runs.

This study does not take into account the removal of aerosols by precipitation (impaction scavenging). Impaction scavenging does not impact in-cloud nucleation strongly, but it can impact ice formation by reducing available IN. It is most effective when clouds develop heavy precipitation at their mature stages as shown by Ekman et al. (2004, 2006). The key mechanisms leading to larger cloud mass with increasing aerosols begin to operate before heavy precipitation develops in the case of deep convection here (cf., Figs. 3 and 5 in Lee et al. (2008a), which show the domain-mean convergence magnitude increases before the onset of heavy precipitation). Also, as stated in Sect. 3.2, the precipitation is very small in the case of stratiform clouds, implying that the impaction scavenging is not significant. Thus, the neglect of impaction scavenging is not expected to change the qualitative nature of the results.

Lee et al. (2008b) reported that in general, increasing wind shear led to the increasing intensity of near-surface convergence and thus cloud mass; also with larger wind shear, the magnitude of cloud-mass increase with increasing aerosols was larger. However, they also showed that the intensity of the convergence could decrease with increasing wind shear at extremely high wind shear. When they increased wind shear to $\sim 0.013 \mathrm{~s}^{-1}$ (a maximum value used in Weisman and Klemp, 1982) as a extremely high shear, the convergence weakened leading to smaller cloud mass at both high and low aerosol. This also led to smaller increase in cloud mass with increasing aerosols than that shown with a comparatively low shear. Hence, it is expected that increasing (decreasing) wind shear increases (decreases) the offset of SCF by LCF in each of high- and low-aerosol runs and that of increasing negative SCF by increasing LCF at high aerosol unless the shear is extremely high. This is consistent with findings of previous studies (e.g., Rotunno et al., 1988; Lafore and Moncrieff, 1989 and references therein). Those studies indicated the important role of interactions between wind shear and near-surface convergence in the intensity of deep convection and an optimal value of wind-shear magnitude for the intensification of deep convection.

Homogeneous freezing of haze particles in this study is assumed to occur instantaneously when a size- and temperature-dependent critical supersaturation with respect to ice is exceeded. The critical supersaturation is determined by a look-up table also used in Phillips et al. (2007). For the construction of the look-up table, aerosols dissolved in haze particles are assumed to be ammonium sulfate. Mangold et al. (2005) reported that the critical supersaturation could be lowered by $30 \%$ from that for the ammonium sulfate maximally with varying chemical compositions of aerosols. With a lower critical supersaturation, more aerosol particles can be nucleated for the identical size distribution of haze particles and ambient temperature. Repeated simulations with the critical supersaturation, which is forced to be lowered by $30 \%$ (every time there is the homogeneous freezing of haze particles), showed that more ice particles were formed than shown in Sect. 3.2. This led to more offset of SCF by LCF than that with the ammonium-sulfate haze particles in each of the high- and low-aerosol runs. This increase in the offset was larger at high aerosol than at low aerosol. This led to larger offset of the increasing negative SCF by increasing LCF than that shown with ammonium-sulfate haze particles at high aerosol.

Acknowledgements. The authors wish to thank Venkatachalam Ramaswamy for valuable discussions. Our thanks also go to Paul Ginoux for the review of the manuscript and Charles Seman for providing us useful post-processors. This paper was prepared under award NA17RJ2612 from the National Oceanic and Atmospheric Administration, U.S. Department of Commerce. The statements, findings, conclusions, and recommendations are those of authors and do not necessarily reflect the views of the National Oceanic and Atmospheric Administration, or the U.S. Department of Commnerce.

Edited by: P. Spichtinger

\section{References}

Ackerman, A. S., Kirkpatrick, M. P., Stevens, D. E., and Toon, O. B.: The impact of humidity above stratiform clouds on indirect aerosol climate forcing, Nature, 432, 1014-1017, 2004.

Bluestein, H. B.: Synoptic-Dynamic Meteorology in Midlatitudes: Volume II: Observations and theory of weather systems (Synoptic-Dynamic Meteorology in Midlatitudes), Oxford University Press, UK, 594 pp., 1993. 
Bryan, G. H., Wyngaard, J. C., and Fritsch, J. M.: Resolution Requirements for the Simulation of Deep Moist Convection, Mon. Weather Rev., 131, 2394-2416, 2003.

Cui, Z., Carslaw, K. S., Yin, Y., and Davies, S.: A numerical study of aerosol effects on the dynamics and microphysics of a deep convective clouds in a continental environment, J. Geophys. Res., 111, D05201, doi:10.1029/2002JD002911, 2006.

Deng, A. and Stauffer, D. R.: On improving 4-km mesoscale model simulations, J. Appl. Meteorol., 45, 361-381, 2006.

Donner, L. J., Seman, C. J., and Hemler, R. S.: Three-dimensional cloud-system modeling of GATE convection, J. Atmos. Sci., 56, 1885-1912, 1999.

Ekman, A. M. L., Wang, C., Wilson, J., Ström, J., and Krejci, R.: Explicit Simulation of Aerosol Physics in a Cloud-Resolving Model: Aerosol Transport and Processing in the Free Troposphere, J. Atmos. Sci., 63, 682-696, 2006.

Ekman, A. M. L., Wang, C., Wilson, J., and Ström, J.: Explicit simulations of aerosol physics in a cloud-resolving model: a sensitivity study based on an observed convective cloud, Atmos. Chem. Phys., 4, 773-791, 2004, http://www.atmos-chemphys.net/4/773/2004/.

Fu, Q.: A new parameterization of an asymmetry factor of cirrus clouds for climate models, J. Atmos. Sci., 64, 4144-4154, 2007.

Gilmore, M. S., Straka, J. M., and Rasmussen, E. N.: Precipitation uncertainty due to variations in precipitation particle parameters within a simple microphysics scheme, Mon. Weather Rev., 132, 2610-2627, 2004.

Grabowski, W. W., Wu, X., and Moncrieff, M. W.: Cloud resolving modeling of tropical cloud systems during phase III of GATE. Part I: Two-Dimensional Experiments, J. Atmos. Sci., 53, 36843709, 1996.

Grabowski, W. W., Wu, X., and Moncrieff, M. W.: Cloud resolving modeling of tropical cloud systems during Phase III of GATE. Part III: Effects of microphysical parameterizations, J. Atmos. Sci., 56, 2384-2402, 1999.

Guo, H., Liu, Y., Daum, P. H., Zeng, X., Li, X., and Tao, W.-K.: Effects of model resolution on entrainment (inversion heights), cloud-radiation interactions, and cloud radiative forcing, Atmos. Chem. Phys. Discuss., 8, 20399-20425, 2008, http://www.atmoschem-phys-discuss.net/8/20399/2008/.

Guo, H., Penner, J. E., Herzog, M., and Xie, S.: Investigation of the first and second aerosol indirect effects using data from the May 2003 Intensive Operational Period at the Southern Great Plains, J. Geophys. Res., 112, D15206, doi:10.1029/2006JD007173, 2007.

Hong, S.-Y. and Pan, H.-L.: Nonlocal boundary layer vertical diffusion in a medium range forecast model, Mon. Weather Rev., 124, 2322-2339, 1996.

Houze, R. A.: Cloud dynamics, Academic Press, 573 pp., 1993.

Jensen, E. J., Kinne, S., and Toon, O. B.: Tropical cirrus cloud radiative forcing: Sensitivity studies, Geophys. Res. Lett., 18, 2023-2026, 1994.

Jiang, H., Feingold, G., and Cotton, W. R.: Simulations of aerosol-cloud-dynamical feedbacks resulting from entrainment of aerosol into the marine boundary layer during the Atlantic Stratocumulus Transition Experiment, J. Geophys. Res., 107, 4813, doi:10.1029/2001JD001502, 2002.

Khain, A. and Pokrovsky, A.: Simulation of Effects of Atmospheric Aerosols on Deep Turbulent Convective Clouds Using a Spectral
Microphysics Mixed-Phase Cumulus Cloud Model. Part II: Sensitivity Study, J. Atmos. Sci., 24, 2983-3001, 2004.

Khain, A., Rosenfeld, D.,and Pokrovsky, A.: Aerosol impact on the dynamics and microphysics of deep convective clouds, Q. J. Roy. Meteorol. Soc., 131, 2639-2663, 2005.

Khain, A., Rosenfeld, D., and Pokrovsky, A.: Simulation of aerosol effects on convective clouds developed under continental and maritime conditions, Geophysical Research Abstracts, 5, 03180, European Geophysical Society, 2003.

Khain, A., BenMoshe, N., and Pokrovsky, A.: Factors determining the impact of aerosols on surface precipitation from clouds: Attempt of classification, J. Atmos. Sci., 65, 1721-1748, 2008.

Khairoutdinov, M. and Kogan, Y.: A new cloud physics parameterization in a large-eddy simulation model of marine stratocumulus, Mon. Weather Rev., 128, 229-243, 2000.

Khvorostyanov, V. I. and Curry, J. A.: Terminal velocities of droplets and crystals: Power laws with continuous parameters over the size spectrum, J. Atmos. Sci., 59, 1872-1884, 2008.

Lafore, J.-P. and Moncrieff, M. W.: A numerical investigation of the organization and interaction of the convective and stratiform regions of tropical squall lines, J. Atmos. Sci., 46, 521-544, 1989.

Lee, S. S., Donner, L. J., Phillips, V. T. J., and Ming, Y.: Examination of aerosol effects on precipitation in deep convective clouds during the 1997 ARM summer experiment, Q. J. Roy. Meteorol. Soc., 134, 1201-1220, 2008a

Lee, S. S., Donner, L. J., Phillips, V. T. J., and Ming, Y.: The dependence of aerosol effects on clouds and precipitation on cloudsystem organization, shear and stability, J. Geophys. Res., 113, D16202, doi:10.1029/2007JD009224, 2008b.

Liljegren, J. C.: Two-channel microwave radiometer for observations of total column precipitable water vapor and cloud liquid water path, 266-269 in proceedings of the fifth symposium on global change, 23-28 January 1994, Nashville, TN, USA, Am. Meteorol. Soc., Boston, MA, USA, 1994.

Lin, Y. L., Farley, R. D., and Orville, H. D.: Bulk parameterization of the snow field in a cloud model, J. Appl. Meteorol., 19, 1065$1092,1983$.

Liou, K. N.: Cirrus clouds and climate in McGraw-Hill Yearbook of Science and Technology, 432 pp., 2005.

Liou, K. N.: Influence of cirrus clouds on weather and climate processes: A global perspective, Mon. Weather Rev., 114, 11671199, 1986.

Lynn, B. H., Khain, A. P., Dudhia, J., Rosenfeld, D., Pokrovsky, A., and Seifert, A.: Spectral (bin) microphysics coupled with a mesoscale model (MM5). Part I: Model description and first results, Mon. Weather Rev., 133, 44-58, 2005.

Lohmann, U.: Global anthropogenic aerosol effects on convective clouds in ECHAM5-HAM, Atmos. Chem. Phys., 8, 2115-2131, 2008, http://www.atmos-chem-phys.net/8/2115/2008/.

Lohmann, U. and Diehl, K.: Sensitivity studies of the importance of dust ice nuclei for the indirect aerosol effect on stratiform mixedphase clouds, J. Atmos. Sci., 63, 968-982, 2006.

Mangold, A.,Wagner, R., Saathoff, H. ,Schurath, U., Giesemann, C., Ebert, V., Krämer, M., and Möhler, O.: Experimental investigations of ice nucleation by different types of aerosols in the aerosol chamber AIDA: Implications to microphysics of cirrus clouds, Meteorologische Zeitschrift, 14, 485-497, 2005.

McFarquhar, G. M. and Black, R. A.: Observations of particle size and phase in tropical cyclones: Implications for mesoscale mod- 
eling of microphysical processes, J. Atmos. Sci., 61, 422-439, 2004.

Pauluis, O. and Garner, S.: Sensitivity of Radiative-Convective Equilibrium Simulations to Horizontal Resolution, J. Atmos. Sci., 63, 1910-1923, 2005.

Pawlowska, H. and Brenguier, J.-L.: An observational study of drizzle formation in stratocumulus clouds for general circulation model (GCM) parameterization, J. Geophys.Res., 108(D15), 8630, doi:10.1029/2002JD002679, 2003.

Phillips, V. T. J. and Donner, L. J.: Cloud microphysics, radiation, and vertical velocities in two- and three-dimensional simulations of deep convection, Q. J. Roy. Meteorol. Soc., 133, 3011-3033, 2006.

Phillips, V. T. J., Donner, L. J., and Garner, S.: Nucleation processes in deep convection simulated by a cloud-system-resolving model with double-moment bulk microphysics, J. Atrmos. Sci., 64, 738-761, 2007.

Pruppacher, H. R. and Klett, J. D.: Microphysics of clouds and precipitation, D. Reidel, 714 pp., 1978.

Ramanathan, V., Cess, R. D., Harrison, E. F., et al.: Cloud-Radiative Forcing and Climate: Results from the Earth Radiation Budget Experiment, Science, 243, 57-63, 1989.

Ramaswamy, V., Boucher, O., Haigh, J., et al.: Radiative forcing of climate change, in: Climate Change 2001: The Scientific Basis, edited by: Houghton, J. T., Ding, Y., Griggs, D. J, et al., Cambridge Univ. Press, New York, 349-416, 2001.

Rosenfeld, D., Lohmann, U., Raga, G. B., et al.: Flood or drought: How do aerosols affect precipitation?, Scicnce, 321, 1309-1313, 2008.

Rotunno, R., Klemp, J. B., and Weisman, M. L.: A theory for strong, long-lived squall lines, J. Atmos. Sci., 45, 463-485, 1988.

Seifert, A., Khain, A., Blahak, U., and Beheng, K. D.: Possible effects of collisional breakup on mixed-phase deep convection simulated by a spectral (bin) cloud model, J. Atmos. Sci., 62, 1917-1931, 2005.
Seinfeld, J. H. and Pandis, S. N.: Atmospheric chemistry and physics: From air pollution to climate change, John Wiley \& Sons, 1326 pp., 1998.

Tao, W.-K., Li, X., Khain, A., Matsui, T., Lang, S., and Simpson, J.: The role of atmospheric aerosol concentration on deep convective precipitation: cloud-resolving model simulations, J. Geophys. Res., 112, D24S18, doi:10.1029/2007JD008728, 2007.

Tong, M. and Xue, M.: Simultaneous estimation of microphysical parameters and atmospheric state with simulated radar data and ensemble square root Kalman filter. Part I: Sensitivity analysis and parameter identifiability, Mon. Weather Rev., 136, 1630 1648, 2008.

Tompkins, A. M. and Craig, G. C.: Radiative-convective equilibrium in a three-dimensional cloud ensemble model, Q. J. Roy. Meteorol. Soc., 124, 2073-2098, 1998.

Weisman, M. L. and Klemp, J. B.: The dependence of numerically simulated convective storms on vertical wind shear and buoyancy, Mon. Weather Rev., 110, 504-520, 1982.

Wendisch, M., Yang, P., and Pilewskie, P.: Effects of ice crystal habit on thermal infrared radiative properties and forcing of cirrus, J. Geophys. Res., 112, D08201, doi:10.1029/2006JD007899, 2007.

Whitby, K. T.: The physical characteristics of sulfur aerosols, Atmos. Environ., 12, 135-159, 1978.

Xu, K.-M., Cederwall, R. T., Donner, L. J., et al.: An intercomparison of cloud-resolving models with the Atmospheric Radiation Measurement summer 1997 Intensive Observation Period data, Q. J. Roy. Meteorol. Soc., 128, 593-624, 2002.

Zhang, M. H., Lin, J. L., Cederwall, R. R., Yio, J. J., and Xie, S. C.: Objective analysis of ARM IOP data: method and sensitivity, Mon. Weather Rev., 129, 295-311, 2001. 